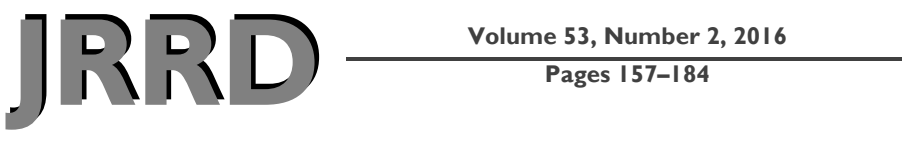

\title{
Prosthetic interventions for people with transtibial amputation: Systematic review and meta-analysis of high-quality prospective literature and systematic reviews
}

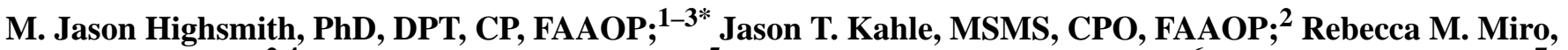 \\ PhD, MBA, CRA; ${ }^{2,4}$ Michael S. Orendurff, PhD; ${ }^{5}$ Amanda L. Lewandowski, DPT; ${ }^{6}$ John J. Orriola, MEd; ${ }^{7}$ \\ Bryce Sutton, PhD; ${ }^{8}$ Jan P. Ertl, MD $^{\mathbf{9}}$ \\ ${ }^{1}$ Department of Veterans Affairs and Department of Defense Extremity Trauma and Amputation Center of Excellence, \\ Washington, DC; ${ }^{2}$ School of Physical Therapy and Rehabilitation Sciences, Morsani College of Medicine, University \\ of South Florida, Tampa, FL; ${ }^{3}$ U.S. Army Reserves, 319th Minimal Care Detachment, Pinellas Park, FL; ${ }^{4}$ Center for \\ Neuromusculoskeletal Research, Morsani College of Medicine, University of South Florida, Tampa, FL; ${ }^{5}$ Orthocare \\ Innovations, Mountlake Terrace, WA; ${ }^{6}$ Select Physical Therapy, Brandon, FL; ${ }^{7}$ Shimberg Health Sciences Library, \\ Morsani College of Medicine, University of South Florida, Tampa, FL; ${ }^{8}$ James A. Haley Veterans' Hospital, Tampa, \\ FL; ${ }^{9}$ Department of Orthopaedic Surgery, School of Medicine, Indiana University, Indianapolis, IN
}

\begin{abstract}
Considering transtibial amputation (TTA) rehabilitation costs and complexity, high-quality literature should inform clinical practice. Systematic reviews (SRs) suggest this is not the case. This article's purpose was to review the highest-quality evidence available to guide clinical practice for TTA regarding five prosthetic intervention areas. Six databases were searched for high-quality SRs and prospective clinical trials (randomized clinical trials [RCTs]). Reviewers screened, sorted, rated (i.e., methodologic quality, bias risk), and extracted article data. Meta-analyses were conducted when possible. Thirty-one references were included (25 RCTs and 6 SRs). Five topical areas emerged (alignment, feet and ankles, interface, postoperative care, pylons). Twenty-three evidence statements were supported by level 2 evidence and eight by level 1 evidence. All RCTs reported randomization and reasonable data presentation. Concealed allocation and blinding were not widely used. Mean attrition was 11\%. SRs included no meta-analyses. Functional level was poorly reported. Grouping feet and ankle components by functional classification enabled meta-analyses, though variance was considerable given the small sample sizes. Prosthetic interventions are generally safe for TTAs. High-quality literature enabled formulation of evidence statements to support select clinical practice areas, though quantity was lacking. Thus, numerous topics related to
\end{abstract}

TTA care lack rigorous evidence. Although blinding in prosthetic research requires increased funding and effort, it could greatly improve the methodologic quality of prosthetic research.

\footnotetext{
Abbreviations: $\mathrm{CI}$ = confidence interval, ESAR = energy storing and release, EWA = early walking aid, FK = flexible keel, $\mathrm{GRF}=$ ground reaction force, $\mathrm{MA}=$ multi-axial, $\mathrm{NIH}=$ National Institutes of Health, PEDro = Physiotherapy Evidence Database Scale, $\mathrm{PTB}=$ patella tendon bearing, RRD = rigid removable dressing, $\mathrm{SA}=$ single axis, $\mathrm{SACH}=$ solid ankle cushion heel, SIGN = Scottish Intercollegiate Guidelines Network, SR = systematic review, TSB = total surface bearing, TTA = transtibial amputation, VASS = vacuum-assisted suspension system, vGRF = vertical ground reaction force, VSP = vertical shock pylon.

*Address all correspondence to $\mathrm{M}$. Jason Highsmith, PhD, DPT, CP, FAAOP; Extremity Trauma and Amputation Center of Excellence, Department of Veterans Affairs and Department of Defense, 8900 Grand Oak Cir (151R), Tampa, FL 33637; 813-558-3936; fax: 813-558-3990.

Email: michael.highsmith@va.gov http://dx.doi.org/10.1682/JRRD.2015.03.0046
} 
Key words: amputee, below-knee, immediate postoperative prosthesis, prosthetic foot, pylon, residual limb, socket, torsion, valgus, varus.

\section{INTRODUCTION}

In the United States alone, approximately 185,000 amputations occur annually [1], contributing to an estimated population of 1.6 million persons living with limb loss [2-3]. Of these, approximately 1.3 million (86\%) have amputation of the lower limb. Twenty-eight percent of people with lower-limb amputation, slightly more than 378,000 individuals, have a transtibial amputation (TTA) [2-3]. Approximately 72 percent of TTAs are attributable to vascular disease. Of those remaining, 7 percent of TTAs are of traumatic etiology [2-3]. There is a higher incidence and prevalence of dysvascular-related amputation associated with advancing age [2-4].

Adding to the subpopulation of people with traumatic amputation within the past $10 \mathrm{yr}$ has been the number of persons who have experienced amputation(s) related to U.S. military service in association with Operations Iraqi Freedom, Enduring Freedom, and New Dawn [5]. Considerable attention has been directed to amputation as a result of the conflicts in the Middle East, which have stimulated technological advancement in prosthetic rehabilitation [6]. While the increase in amputations within the military sector is substantial, from a societal perspective, the population of those with military-associated amputation(s) is comparatively small. There have been 1,221 persons engaged in military service who have experienced 1,631 amputations from 2001 to 2011 [5]. Of these, 683 amputations (or $41.9 \%$ ) were at the transtibial level and 366 people experienced multiple amputations. Many of these included a TTA [5]. Those individuals who have lost a limb (or limbs) in military service are commonly within the third decade of life and will require a much longer duration of care over their remaining lifetime compared with those who lose limbs to vascular disease, which is more common after the fourth or fifth decade of life [5]. It is likely that those who lose a limb in military service have higher functional ambulation standards that will challenge the healthcare system accustomed to providing care for persons who have lost limbs to vascular disease.

It is known that persons with TTA develop secondary conditions related to overuse of the sound limb, prosthetic malalignment of components relative to interface, and other factors. These conditions may include degenerative joint disease, osteopenia, postural issues, low back pain, skin issues, and others [7-8]. Nevertheless, many individuals with TTA lead functional lifestyles [9], at times participating in sports and athletic pursuits [10]. Incorporation of a transtibial prosthesis is routinely part of the rehabilitation and reintegration plan [11]. Typical prostheses ideally include a comfortable, optimally aligned socket interface, pylon, and foot. Prior to providing this prosthesis, some form of postamputation care is common. Problematically, there is no consensus to guide any of the aforementioned prosthetic elements. The common inclusion of a prosthesis is, however, a considerable healthcare expense over the lifetime for the person with TTA. For example, Blough et al. estimated that prosthetic costs over the lifetime for an individual with unilateral lower-limb amputation could range from $\$ 0.5$ million to $\$ 1.8$ million, depending on the number of prostheses in service at a given time, the type of prostheses, and other factors [12]. Collectively, total care for a person with amputation of dysvascular etiology had an estimated U.S. societal cost of $\$ 4.3$ billion in 1996, and Medicare reimbursed $\$ 655$ million worth of lower-limb prosthetic services in 2009 [13-14].

Given the remarkable costs associated with hospital and facility fees, amputation rehabilitation, and prosthetic provision, it is problematic that so much of the associated literature is noncommittal, inconclusive, and ultimately unable to guide clinical practice or reimbursement. For example, prominent reviews on the subjects of foot prescription [15] and postoperative management [16] conclude by indicating that no clinical recommendations can ultimately be made given a lack of evidence or of high-quality evidence.

Coupling newly available evidence, rehabilitation techniques, and technologies with a broader focus aimed across the spectrum of rehabilitation timing and interventions may permit the development of improved clinical management recommendations. This may be particularly true if the highest quality of comparative efficacy studies and systematic reviews (SRs) are the target literature. As new literature, techniques, and technologies have emerged, much due to the natural progression of clinical practice and science and some attributable to new societal challenges such as war in the Middle East and reimbursement issues domestically, new problems and challenges have also emerged. Given that much of the aforementioned literature is inconclusive and that many 
of the related reviews were completed nearly a decade ago, it is timely to review the currently available highquality literature available to address contemporary challenges and to better guide current practice. Therefore, the purpose of this literature SR was to evaluate the highest quality of evidence available to guide prosthetic clinical practice for adult patients with TTA regarding prosthetic management in five specific areas of interest: alignment, feet and ankles, interface, postoperative care, and pylons.

\section{METHODS}

A multidisciplinary review team planned methodology in accordance with those used previously in prosthetic research [17] in addition to standards established by the PRISMA (Preferred Reporting Items for Systematic Reviews and Meta-Analyses) Statement [18-19]. Reviewers had advanced graduate degrees or professional healthcare training in physical therapy, prosthetics, or medicine. Specifically, the team included physical therapists, prosthetists, an orthopedic surgeon, a health economist, and information scientists. The team met on three occasions and outlined search methodology to include multiple databases and key search terms (primary and secondary) that would assure identification of available high-quality evidence to address prosthetic interventions for those with TTA. Search methodology was based on a broad view of TTAs with regard to prosthetic intervention. Preliminary test searches were conducted and outcomes previewed at presearch meetings to assure adequate inclusion of key articles in terms of both quantity and quality within the five areas of interest. The search statement was planned to be sensitive to this condition and/or intervention, but realizing how the prosthetic and/ or amputation literature can sometimes be multisubject (i.e., patients with TTA might be grouped with others, such as patients with transfemoral amputation), the search statement was enhanced to include any prosthesis involving any part of the leg. This more inclusive strategy necessitated more rigorous screening postsearch in order to capture pertinent articles. The primary search term sets were-

- (prosthe* OR "Prostheses and Implants” OR prosthesis OR prostheses OR preprosthe* OR pre-prosthe*).

- (((transtibial OR trans-tibial OR trans tibial OR below knee OR bka OR tta OR Leg [Mesh] OR leg OR legs
OR lower limb OR lower limbs OR lower limb OR lower extremit* OR “Lower Extremity” [Mesh]))).

Subsequently, the large retrieval from the statement would be combined with selected prosthetic (secondary) terms to refine. The secondary search term set was-

- air limb OR air splint OR air* OR airleg OR Amputation Stumps [Mesh] OR artificial limb OR bandage OR bandag* OR Bandages [Mesh] OR contracture* OR “Contracture” [Mesh] OR cost OR doff [tiab] OR donning [tiab] OR don [tiab] OR soft dress* [tiab] OR econom* [tiab] OR Economics [Mesh] OR elastic* OR fit OR fitt* OR liner OR lined OR lining OR piston* [tiab] OR pneumatic OR prognos* OR "Prognosis” [Mesh] OR “range of motion” OR Range of Motion, Articular [Mesh] OR rigid OR rom OR sock OR socket OR stump* OR suspension*.

Between March 11 and 19, 2013, the following databases were searched: (1) PubMed, (2) CINAHL, (3) RECAL Legacy, (4) Cochrane Database of Systematic Reviews, (5) PubMed Central-National Institutes of Health (NIH) Research Publication Database, and (6) Web of Science. The following date limits were implemented as part of the database search parameters: 1997 (January 1) to 2013 (January 1). The search was repeated by a pair of separate information scientists $3 \mathrm{mo}$ after the initial search.

\section{Article Screening}

Resulting references were exported to EndNote reference management software (version X6, Thomson Reuters; Philadelphia, Pennsylvania). Duplicate references were eliminated. Remaining articles were preliminarily sorted into intervention studies (clinical trials) or SRs. Exclusion criteria were selected to eliminate articles with lower evidence levels and assure maximal generalizability to the adult with TTA living in a developed country. Foreign language articles were eliminated relative to prohibitive costs associated with translation. Clinical trials were screened for exclusion using the following initial criteria within EndNote:

1. Case studies, case report, case series.

2. Foreign language (i.e., non-English language).

3. Developing countries.

4. Nonhuman subject (i.e., material science, finite element studies).

5. Pediatric studies.

6. Technical notes.

7. Retrospective studies. 
8. Observational and survey-only studies.

9. Economic studies (eliminated post hoc for a separate, future analysis).

Following the EndNote search using the aforementioned exclusion criteria, the remaining intervention articles were divided equally between reviewers. Each article was assigned a primary and secondary reviewer. The reviewers independently screened references according to inclusion and exclusion criteria and classified them as either (1) pertinent, (2) not pertinent, or (3) uncertain pertinence. Full-text articles were reviewed for all citations classified as pertinent or uncertain pertinence. Disagreement regarding citations of uncertain pertinence was resolved by discussion at weekly follow-up meetings with the two other reviewers. Review of full-text articles and associated discussion led to group consensus and ultimate inclusion or exclusion. Exclusion criteria applied during the EndNote search were applied at this stage of screening. Inclusion criteria applied were-

1. Peer-reviewed, prospective clinical intervention trial or SR.

2. Prosthetic intervention in one or more of the five topical interest areas.

3. Published within the aforementioned time frame.

\section{Quality Assessment}

Once pertinent clinical trial articles were screened and sorted, methodologic quality and risk of bias was independently assessed by the paired raters in order to assist with determining the level of evidence to support the topics of interest. The Physiotherapy Evidence Database Scale (PEDro) was used to determine methodologic quality of clinical topics because it has fair to good reliability for application in rehabilitation clinical trials and is recognized internationally [20]. The scale results in a 0 to 10 score, with higher scores reflecting higher methodologic quality, based on 11 criteria. The first criterion, regarding eligibility, is not scored. Criteria 2 to 11 include determination of the presence of other methodologic attributes such as blinding, rating attrition, reporting of data in terms of point and variance measures, and others. To receive a point in each of these remaining 10 criteria, the criteria must be clearly stated in the study resulting in a "yes" answer for presence of that item, resulting in the awarding of 1 point. If an item is not clearly stated, it received a "no" answer and received no point for that criterion. A PEDro score of $\geq 6 / 10$ is considered to have high methodologic quality, whereas scores
$<6 / 10$ are considered to have low methodologic quality [20]. Because the purpose of this SR was to identify intervention studies with sufficient methodological strength to guide clinical practice, clinical trial articles scoring $\leq 5 / 10$ were excluded. The PEDro was used only to rate methodologic quality for the intervention studies (i.e., clinical trials) because it is not designed to rate SRs.

Following the rating of methodologic quality, two Scottish Intercollegiate Guidelines Network (SIGN) 50 assessment forms (one each for clinical trials and SRs) were used to (1) assess internal validity, (2) assess degree of bias, and (3) extract useful data from pertinent references [21]. Included article authors were not contacted for any clarification or raw data requests. Answers from the SIGN 50 checklists are not weighted. According to the SIGN 50, bias risk is classified as either-

1. Low-All or most criteria from the internal validity assessment are satisfied. Study conclusions would not likely be altered if methods were changed.

2. Moderate-Some from the internal validity assessment are satisfied. Study conclusions would not likely be altered if methods were changed.

3. High-Few or no criteria from the internal validity assessment are satisfied. Study conclusions are likely or very likely to be altered if methods were changed.

SIGN 50 bias risk rating was not used to determine inclusion or exclusion of clinical trials because the PEDro was used for this.

Reviewers equally divided and reviewed SR articles first for pertinence, as described previously for clinical trials. Once pertinence was established, the SIGN 50 classification was applied and SRs with high bias risk were not included. As part of the determination of pertinence, SRs were excluded prior to bias risk assessment if they-

1. Covered a selected prosthetic intervention topic, buta. Failed to document a repeatable review methodology. b. Were exclusively editorial.

2. Did not address a selected prosthetic intervention topic (i.e., reported on attributes of measurement techniques).

Following assessment of methodologic quality and bias risk, the level of evidence was determined by using the model designed by the Centre for Evidence-Based Medicine [22]. Briefly, this model assists in determining the level of evidence supporting an evidence statement based on multiple factors, including the study design(s) and magnitude of effect in the supporting reports. For instance, an SR of randomized intervention trials would 
represent level 1 evidentiary support, whereas level 2 evidence would include a randomized trial or an observational study with a dramatic effect. Levels of evidence are somewhat adjustable in accordance with quality, effect size, and other factors.

\section{Analysis}

Data pooling (i.e., meta-analyses) was conducted when homogeneous data were available. When data pooling was possible, mean difference with 95 percent confidence interval (CI) was calculated and significance was determined a priori to be $p \leq 0.05$ [23]. Effect sizes (Cohen $d$ ) [24] were therefore calculated for articles with available data using formulas based on independent $t$ tests. Use of this method versus a calculation that controls for data dependency is controversial. For instance, effect sizes tend to be larger when data dependency is considered. Limitations include requiring more information such as the correlation coefficient between data being examined [24]. Articles reviewed commonly had limited information; therefore, we chose to use the calculation based on independent groups, acknowledging this is a conservative approach.

\section{Sorting by Topic}

Full-text articles were sorted by reviewers for pertinence in one or more of the five selected topics following procedures for screening and eligibility determination.

\section{RESULTS}

The search resulted in 8,796 articles (Figure 1). The 3 mo repeat search yielded an identical result. Using EndNote, 1,724 duplicate references were eliminated. Additionally, exclusion screening using EndNote eliminated an additional 6,937 references. This left 135 references to be manually screened by the reviewer teams. Of the manual screening, which included quality assessment, 104 references were eliminated, leaving 31 high-quality references available for inclusion in the review. Of these, 25 were clinical trials and 6 were SRs.

In total, this review spanned 16 yr of literature. Thirty-one total evidence statements were made, whereby the majority (23/31) were supported by level 2 evidence and the remaining (8/31) were supported by level 1 evidence. This suggests that using only high-quality literature, an estimated 1.4 evidence statements are available per year or that it takes approximately 2 yr for an empirical evidence statement to become available that has level 1 evidentiary support.

\section{Funding and Sponsorship}

In 31 total articles, 32 funding disclosures were made. Of the total 32, 20 (63\%) disclosures were government sponsors. Nations and countries included in the government sponsors were the United States (Department of Veterans Affairs, Department of Education, National Science Foundation), China (Hong Kong), United Kingdom, Sweden, the Netherlands, Canada, and France. Considering eligibility criteria, the most represented sponsor was the U.S. Department of Veterans Affairs, with 30 percent of the government sponsorships and 19 percent of total sponsorships. There were 5 (16\%) industry sponsors, 3 (10\%) academic institutional sponsors, and 3 (10\%) nonprofit organization sponsors. Government was the largest sponsor; however, 8/31 (26\%) articles disclosed no funding source.

\section{Collective Quality Assessment}

Twenty-five clinical trials (Table 1) met inclusion criteria and were identified as high-quality. Of these, 12 scored $6 / 10$ and the rest (13) scored 7/10 for methodologic quality on the PEDro. All 25 of the identified highquality clinical trials reported randomization and data presentation that included point and variance measures for at least one outcome. Less than half of the clinical trials included concealed allocation (6/25) and subject blinding (10/25). Only two clinical trials reported clinician blinding, and only three reported blinded raters. The majority of the clinical trials scored a moderate bias risk (21/25), with two rating a high bias risk and two rating a low bias risk. The two studies with high bias risk were in the interface topic. These two had an estimated 48 percent attrition (mean) compared with the entire sample, which had 11 percent attrition. The range of attrition across all included studies was 0 to 75 percent. The low bias risk studies included a postoperative care study and a pylon study. The reference with the single highest attrition (75\%) scored a high bias risk [37].

The SRs included no meta-analyses and covered between one and six databases. Bias risk was low in three of six SRs [15,50-51], whereas the remaining three had moderate bias risk [16,52-53].

It was determined at this point that the five topical areas were adequately supported sufficient to proceed with the review and synthesis. Within the five topical 


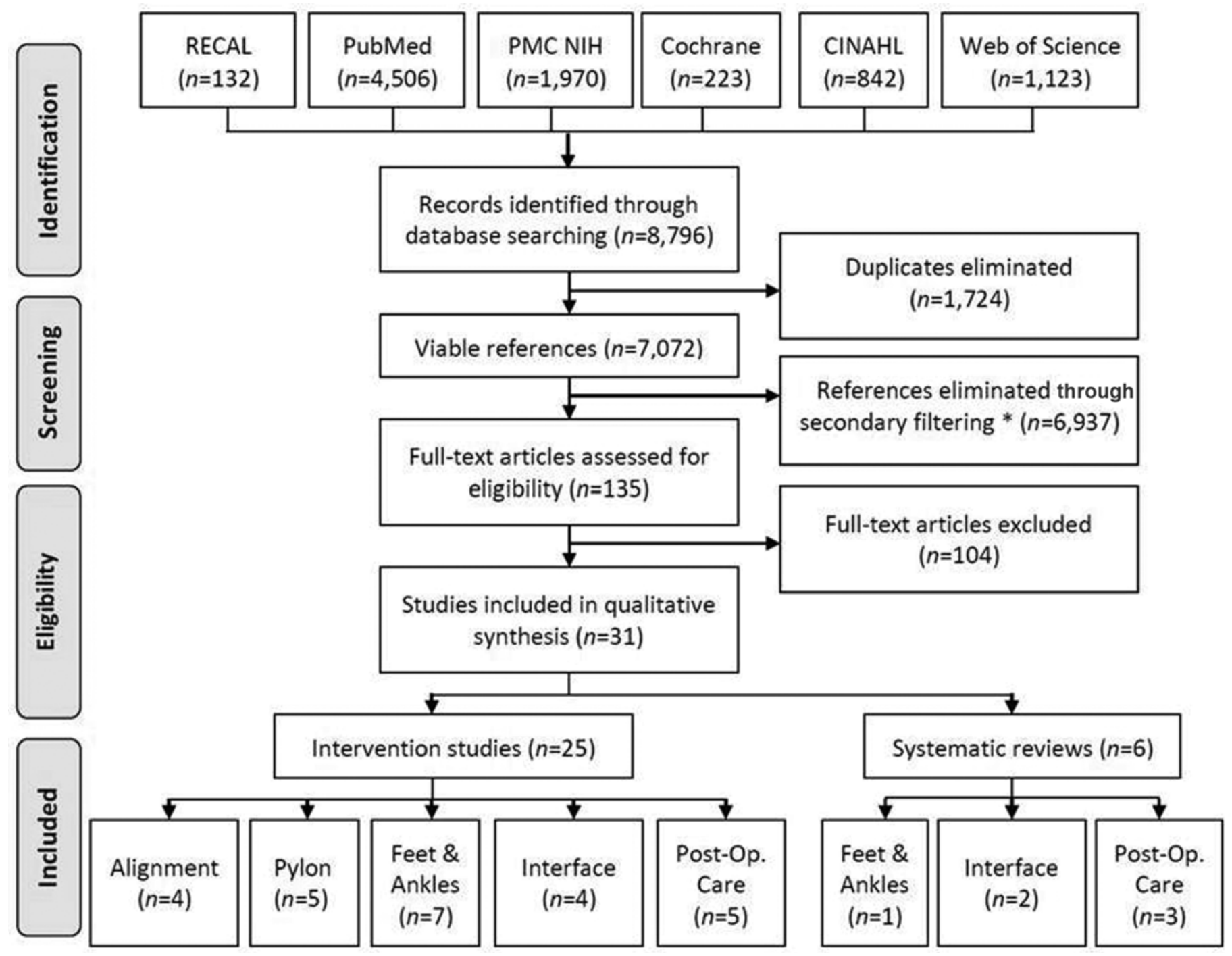

Figure 1.

Study flow diagram. *References eliminated through secondary filtering within reference management software (see "Methods" section). PMC-NIH = PubMed Central-National Institutes of Health, Post-Op = postoperative.

areas, 19 specific prosthetic interventions emerged as follows:

1. Alignment (considered a single intervention type).

2. Feet and ankles (7 intervention types).

3. Interface (4 intervention types).

4. Postoperative care (3 intervention types).

5. Pylon (4 intervention types).

Three of the five topics (feet and ankles, interface, and postoperative care) were supported by both clinical trials and SRs.
Articles in the alignment, feet and ankles, and pylon sections reported no adverse event (i.e., falls, injury resulting from fall) associated with prosthetic use or any specific technique or component included in the review. Further, no articles in these sections concluded that prosthetic nonusage was effective or an option for the person with TTA. This could also suggest subject selection bias in the included studies. The interface and postoperative care studies reported attrition in some cases prior to, and in other cases following, prosthetic intervention. In the 
Table 1.

Methodologic ratings of included clinical trials using Physiotherapy Evidence Database Scale (PEDro).

\begin{tabular}{|c|c|c|c|c|c|c|c|c|c|c|c|c|c|}
\hline \multirow{2}{*}{ Author } & \multicolumn{12}{|c|}{ PEDro Score } & \multirow{2}{*}{ Topic } \\
\hline & 1 & 2 & 3 & 4 & 5 & 6 & 7 & 8 & 9 & 10 & 11 & Sum & \\
\hline Boone et al., 2012 [25] & 1 & 1 & 0 & 1 & 1 & 0 & 0 & 1 & 1 & 1 & 1 & 7 & Alignment \\
\hline Grumillier et al., 2008 [26] & 1 & 1 & 0 & 1 & 0 & 0 & 0 & 1 & 1 & 1 & 1 & 6 & \\
\hline Beyaert et al., 2008 [27] & 1 & 1 & 0 & 1 & 0 & 0 & 0 & 1 & 1 & 1 & 1 & 6 & \\
\hline Van Velzen et al., 2005 [28] & 1 & 1 & 1 & 1 & 0 & 0 & 0 & 0 & 1 & 1 & 1 & 6 & \\
\hline Zmitrewicz et al., 2006 [29] & 1 & 1 & 0 & 1 & 1 & 0 & 0 & 1 & 1 & 1 & 1 & 7 & Feet and Ankles \\
\hline Underwood et al., 2004 [30] & 1 & 1 & 0 & 1 & 0 & 0 & 0 & 1 & 1 & 1 & 1 & 6 & \\
\hline Hsu et al., 1999 [31] & 1 & 1 & 0 & 1 & 0 & 0 & 0 & 1 & 1 & 1 & 1 & 6 & \\
\hline Yack et al., 1999 [32] & 0 & 1 & 0 & 1 & 0 & 0 & 0 & 1 & 1 & 1 & 1 & 6 & \\
\hline Perry et al., 1997 [33] & 0 & 1 & 0 & 1 & 0 & 0 & 0 & 1 & 1 & 1 & 1 & 6 & \\
\hline Postema et al., 1997 [34] & 1 & 1 & 0 & 1 & 1 & 0 & 1 & 1 & 0 & 1 & 1 & 7 & \\
\hline Postema et al., 1997 [35] & 0 & 1 & 0 & 0 & 1 & 0 & 1 & 1 & 1 & 1 & 1 & 7 & \\
\hline Traballesi et al., 2012 [36] & 1 & 1 & 1 & 1 & 0 & 0 & 0 & 1 & 1 & 1 & 1 & $7^{*}$ & Interface \\
\hline Klute et al., 2011 [37] & 1 & 1 & 1 & 1 & 0 & 0 & 0 & 0 & 1 & 1 & 1 & $6^{*}$ & \\
\hline Coleman et al., 2004 [38] & 1 & 1 & 0 & 1 & 0 & 0 & 0 & 1 & 1 & 1 & 1 & 7 & \\
\hline Beil et al., 2002 [39] & 0 & 1 & 0 & 1 & 0 & 0 & 0 & 1 & 1 & 1 & 1 & 6 & \\
\hline Mazari et al., 2010 [40] & 1 & 1 & 1 & 1 & 0 & 0 & 0 & 1 & 1 & 1 & 1 & 7 & Postoperative Care \\
\hline $\begin{array}{l}\text { Johannesson et al., } 2008 \\
\text { [41] }\end{array}$ & 1 & 1 & 1 & 0 & 1 & 1 & 1 & 0 & 0 & 1 & 1 & 7 & \\
\hline Woodburn et al., 2004 [42] & 1 & 1 & 1 & 1 & 0 & 1 & 0 & 0 & 0 & 1 & 1 & $7^{\dagger}$ & \\
\hline Graf \& Freijah, 2003 [43] & 1 & 1 & 0 & 1 & 0 & 0 & 0 & 1 & 1 & 1 & 1 & 6 & \\
\hline Vigier et al., 1999 [44] & 1 & 1 & 0 & 1 & 0 & 0 & 0 & 1 & 1 & 1 & 1 & 6 & \\
\hline Segal et al., 2010 [45] & 1 & 1 & 0 & 1 & 1 & 0 & 0 & 1 & 1 & 1 & 1 & $7^{\dagger}$ & Pylon \\
\hline Jones et al., 2006 [46] & 0 & 1 & 0 & 1 & 1 & 0 & 0 & 1 & 1 & 1 & 1 & 7 & \\
\hline Klute et al., 2006 [47] & 1 & 1 & 0 & 1 & 1 & 0 & 0 & 0 & 1 & 1 & 1 & 6 & \\
\hline Lee et al., 2006 [48] & 0 & 1 & 0 & 1 & 1 & 0 & 0 & 1 & 1 & 1 & 1 & 7 & \\
\hline Berge et al., 2005 [49] & 1 & 1 & 0 & 1 & 1 & 0 & 0 & 1 & 0 & 1 & 1 & 7 & \\
\hline
\end{tabular}

latter cases, however, most attrition was not directly attributed to the intervention (i.e., infection, death related to comorbidity).

\section{Per Topic Assessment}

\section{Alignment}

Alignment articles included four clinical trials that used repeated-measures designs (Table 2.) [25-28]. None included rater or clinician blinding. Three of the four alignment articles scored 6/10 in terms of methodologic quality, and the highest PEDro score of the alignment articles was $7 / 10$ in one article [25]. Largely because of a lack of concealment and blinding, bias risk was moderate in all of the alignment articles. Data were insufficient to calculate effect sizes in some of the align- ment outcomes. However, where available and when significant, the magnitude of effect that malalignment had on various biomechanical outcomes ranged from small (0.14) relative to initial hip kinematic peak with prosthetic internal rotation malalignment to large (1.4) relative to the difference in stance phase duration between sound and prosthetic limbs with malalignment into internal rotation compared with initial alignment [26]. More differences tended to be large, particularly related to measures about the ankle. Nondisabled control subjects ( $n=15$ ) were used in one study (2 references) [26-27] to provide a context of so-called normal (i.e., nondisabled) biomechanics, and problematically, only a single female subject is clearly identified to have participated in the experiments related to the alignment topic [25]. Alignment data represent the collective study of 48 subjects 
Table 2.

Alignment topic study data summary.

\begin{tabular}{clll}
\hline \multicolumn{1}{c}{ Author } & \multicolumn{1}{c}{ Interventions } & \multicolumn{1}{c}{ Outcome Measures } & \multicolumn{1}{c}{ Major Findings } \\
\hline Boone et al., 2012 [25] & $\begin{array}{l}\text { 1 nominally aligned vs 16 } \\
\text { malaligned conditions. }\end{array}$ & $\begin{array}{l}\text { Ability to detect true } \\
\text { malalignments' magnitude } \\
\text { and plane using specialized }\end{array}$ & $\begin{array}{l}\text { Subjects able to perceive more } \\
\text { extreme coronal and sagittal } \\
\text { malalignments. Instrumenta- } \\
\text { software. Sensitivity, specific- } \\
\text { tion may be useful to detect } \\
\text { minor malalignments, particu- }\end{array}$ \\
& & $\begin{array}{l}\text { ity, and likelihood ratios cal- } \\
\text { culated for each possible }\end{array}$ & larly in sagittal plane.
\end{tabular}

Grumillier et al., 2008 [26]

Initial alignment vs transverse rotational malalignment (internal and external rotation).
Beyaert et al., 2008 [27]

Van Velzen et al., 2005 [28]
Initial alignment vs transverse rotational malalignment (internal and external rotation). come.

Gait comfort, spatiotemporal gait parameters, hip dynamics.

Prosthetic malalignment into internal rotation was less comfortable and showed differences in spatiotemporal and hip dynamics compared with initial alignment. Total hip work increased as compensatory strategy to enhance diminished shock absorption provided by prosthesis.

Gait comfort, spatiotemporal gait parameters, knee kinetics, ground reaction force.

Sound limbs experienced increased knee flexion and greater total work compared with prosthetic side. Uncomfortable gait caused by internally rotated malalignment does not alter prosthetic side knee kinetics but does alter sound side knee kinetics, suggesting compensatory mechanism.

Transverse malalignment of foot resulted in differences in step duration and gait kinetics predominantly at ankle during late stance.

8 malalignments of $15^{\circ}$ mag- Spatiotemporal and kinetic nitude (varus, valgus, flexion, gait parameters. extension, endorotation, exorotation, plantar flexion, and dorsiflexion) vs initial alignment.
(15 nondisabled and 33 with TTA) who tended to be in the fifth decade of life (interquartile mean: $46.5 \mathrm{yr}$ ), were of predominantly traumatic etiology (except for 3 subjects [28]), and were adapting to malalignment over the course of several minutes. Additionally, while most eligibility criteria from these studies suggest subjects had to report to a laboratory and ambulate independently, specific functional level was not provided. Attrition was only 5 percent in this review topic.

Following article synthesis, the following empirical evidence statements were made with regard to alignment. In community-ambulating persons with TTA-
1. Prosthetic foot malalignment into internal rotation increases sound side total hip and knee work, increases sound side knee flexion, and decreases gait comfort [26-27].

2. Transverse plane prosthetic foot malalignment results in mediolateral kinetic differences in gait, predominantly at the prosthetic ankle during late stance compared with the sound side and with a reference alignment [28].

3. Prosthetic component malalignment in the coronal and sagittal planes is detectable by the user when $\geq 3^{\circ}$ angularly or $\geq 10 \mathrm{~mm}$ linearly [25]. 
Each of these three evidence statements are supported by a single high-quality clinical study, and thus, supported by level 2 evidence [22].

\section{Feet and Ankles}

Seven clinical trials and one SR [15] supported the feet and ankles topic (Table 3). Six [29,31-35] intervention

Table 3.

Feet and ankles topic study data summary.

\begin{tabular}{cll}
\hline Author & \multicolumn{1}{c}{ Interventions } & \multicolumn{1}{c}{ Outcome Measures } \\
\hline Zmitrewicz et al., 2006 [29] & SACH, SACH + MA ankle, & AP GRF impulse, peak GRF \\
& ESAR, ESAR + MA ankle. & $\begin{array}{l}\text { braking, propulsion impulse } \\
\text { duration. }\end{array}$
\end{tabular}

Underwood et al., 2004 [30] FK, ESAR.

Hsu et al., 1999 [31]

SACH, ESAR, ESAR + VSP.

SACH, ESAR, ESAR + VSP.

Yack et al., 1999 [32]

Perry et al., 1997 [33]

SA, ESAR $\times 2$.

Postema et al., 1997 [34] SA, MA, ESAR $\times 2$.

Postema et al., 1997 [35]
SA, MA, ESAR $\times 2$.
Triplanar peak joint moments and powers, ratings of perceived stability and mobility.

Energy cost, gait efficiency, relative exercise intensity.

Net joint moment, power, work values (ankle, knee, hip).
Stride characteristics, joint motion, angular joint velocity, joint compliance.

Walking speed, cadence, ROM (hip, knee, ankle), impulse of deceleration and acceleration phase of GRF's AP component, ESAR, total ankle power.

Ad hoc questionnaires.

\section{Major Findings \\ MA ankles added to prosthetic feet improve residual limb pro- pulsive impulse generation and load symmetry. 14/15 subjects preferred MA ankles added to feet. 11/15 subjects preferred prosthesis that best improved loading symmetry.}

ESAR feet increased prosthetic reliance for gait propulsion and stability with minimal compensations at remaining joints.

ESAR + VSP appears to have positive effect on energy cost, gait efficiency, and relative exercise intensity compared with SACH foot and ESAR during walking and running.

Stair ascent peak power amplitudes different between amputated and sound side hip, knee, and ankle. SACH required increased hip work; thus, ESAR feet offer potential advantage when walking stairs.

Lack of shank-foot coupling in SA foot creates more rapid plantar flexion and dorsiflexion while balanced on heel in gait.

Ankle ROM with SA foot larger than ESAR and MA feet. Energy release of Dynamic ESAR greater than Quantum ESAR (20\%), SA (40\%), and MA (20\%) feet.

Subjects less able to discern actual functional differences among feet types but may have clear preferences for certain components. Occupational needs and perceived stability are among factors attributed to subject preference.

$\mathrm{AP}=$ anteroposterior, ESAR $=$ energy storing and release, $\mathrm{FK}=$ flexible keel, $\mathrm{GRF}=$ ground reaction force, $\mathrm{MA}=$ multi-axial, $\mathrm{ROM}=$ range of motion, $\mathrm{SA}=$ single axis, SACH = solid ankle cushion heel, TTA = transtibial amputation, VSP = vertical shock pylon. 
studies used repeated-measure designs, and one [30] used a crossover design. Two studies [29,34-35] used a 4-way comparison, three used a 3-way comparison [31-33], and one [30] used a 2-way comparison of feet. No studies of athletic or microprocessor foot and/or ankle systems met the inclusion criteria. The identified seven categories of feet and ankles meeting inclusion and thus reviewed were as follows:

1. Solid ankle cushion heel (SACH) feet [29,31-32].

2. Single axis (SA) feet [33-35].

3. Multi-axial (MA) feet and/or ankle systems [29,34-35].

4. Flexible keel (FK) feet [30].

5. Energy storing and release (ESAR) feet [29-35].

6. ESAR + MA feet [29].

7. ESAR + vertical shock pylon (VSP) feet [31-32].

Three of the seven feet studies scored $7 / 10$, and the remaining four scored $6 / 10$ for methodologic quality. Bias risk within this section was moderate in all of the included articles. No study in the feet and ankles topic concealed intervention allocation. Only one study incorporated double blinding [34-35].

Conclusions from the feet and ankles topic are based on 56 people with TTA. Of these, 58 percent were of dysvascular etiology, 39 percent were of traumatic etiology, and 18 percent were female. As in the alignment section, 15 nondisabled controls were studied to provide a context for comparison of TTA data relative to normal function [32-33]. Subjects were provided a range of accommodation times with study feet, from $30 \mathrm{~min}$ [30] to $4 \mathrm{wk}$ $[29,33]$. The interquartile mean age of the reported subjects' sample mean ages is $46.4 \mathrm{yr}$. As in the alignment section, most eligibility criteria from these studies suggest subjects had to report to a laboratory, ambulate independently, and in some cases, be able to perform specific functional tasks (i.e., run); however, specific functional level was not provided. Attrition was also low in this review topic (7\%). Effect sizes within this section ranged from small (0.12) when considering subjective differences between feet [35] to large (3.09) relative to ankle joint velocity into plantar flexion between controls and the Seattle LightFoot in TTA [33].

The SR on prosthetic foot prescription searched six databases and was rated as having low bias risk [15]. The SR on prosthetic foot prescription used different rating strategies than those in the current study, and studies included ranged from 1983 to 2006. This represents $10 \mathrm{yr}$ of overlap with the present review. Five articles [3031,33-35] were identified as being included in both reviews, one article [32] was rejected from the SR that was included here, and one article [29] was included here that was not yet published for inclusion into the former SR. Further, the SR reported feet and ankle outcomes by component brand and model as opposed to functional category (i.e., SA, MA, ESAR). Grouping component outcomes by functional category enabled meta-analyses.

For aggregate analyses, the mean walking speed across all studies for all feet and ankle types in this section was $1.24 \mathrm{~m} / \mathrm{s}$, whereas the mean for ESAR feet was $1.29 \mathrm{~m} / \mathrm{s}$ (95\% CI: $1.10-1.40 \mathrm{~m} / \mathrm{s}$ ) and the mean for MA units was $1.14 \mathrm{~m} / \mathrm{s}(95 \% \mathrm{CI}: 1.02-1.36 \mathrm{~m} / \mathrm{s})$, though the difference was not statistically significant $(p=0.36)$ and the variance was considerable (Figure 2). Additionally, two studies reported significantly increased early stance peak plantar flexion with SA feet compared with MA and various ESAR feet [33-34]. Meta-analysis revealed a significant $(p=0.005)$ increase in this outcome with SA feet (95\% CI: $\left.9.4^{\circ}-11.9^{\circ}\right)$ compared with ESAR feet $(95 \%$
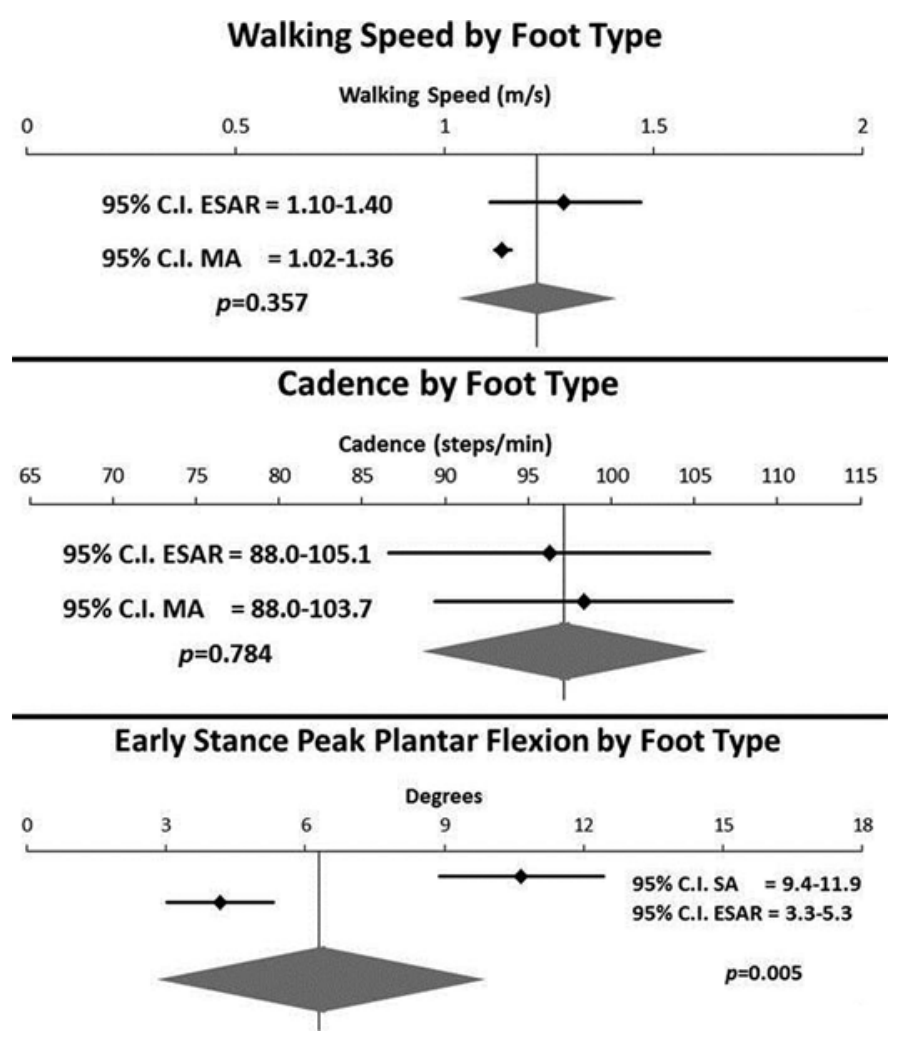

Figure 2.

Meta-analyses from feet and ankles category. $\mathrm{Cl}=$ confidence interval, ESAR = energy storing and release, $\mathrm{MA}=$ multi-axial, $\mathrm{SA}=$ single axis. 
CI: $3.3^{\circ}-5.3^{\circ}$ ), which agrees with the large effect (Cohen $d \geq 0.80$ ) also calculated from the measurements from these studies [33-34].

Following article synthesis, the following empirical evidence statements were made with regard to feet and ankle units. In community-ambulating persons with TTA walking at self-selected speed-

1. SA feet accelerate sagittally in a greater range of motion compared with MA and ESAR feet [15,33-34].

2. Adding MA ankle function to a prosthetic foot increases residual-limb propulsive impulses, leg load symmetry, and preference compared with the same foot without MA foot function [29].

\section{ESAR feet-}

a. Increase prosthetic propulsion and stability and minimize intact joint compensations during gait compared with FK feet [30].

b. Improve stair ascent by reducing involved side hip moment and power requirements compared with SACH feet [32].

c. Decrease fatigue compared with SA and MA feet [35].

d. Reduce walking energy cost and increase gait efficiency and stride length compared with SACH feet [15,31].

4. ESAR + VSP feet-

a. Improve stair ascent by reducing involved side hip moment and power requirements and increasing prosthetic ankle moment compared with SACH and ESAR feet [32].

b. Reduce energy cost and increase gait efficiency and relative exercise intensity compared with SACH and ESAR feet in walking and running [31].

Empirical evidence statements 1 and 3d are supported by high-quality intervention studies and an SR (level 1 evidence). Further strengthening statement 1, meta-analysis revealed a significant $(p=0.005)$ increase in early stance phase peak plantar flexion compared with ESAR feet (Figure 2). The remaining statements are supported by single high-quality clinical studies and are thus supported by level 2 evidence [22].

\section{Interface}

Four clinical trials and two SRs support the interface topic (Table 4). The clinical trials included a parallel design trial [36], two repeated-measures designs [37,39], and one crossover study [38]. Two of the studies were rated $7 / 10$, and two received $6 / 10$ methodologic quality ratings. No points were awarded for blinding in these studies. Two of these studies had high bias risk partially attributable to two problems: (1) attrition at or above 20 percent and (2) no reported intention-to-treat analysis plan. The other two clinical studies had moderate bias risk.

Including both suspension and liner type, the four interface designs studied include-

1. Vacuum-assisted suspension system (VASS) [36-37,39].

2. Total surface bearing (TSB) $[36,39]$.

3. Patella tendon bearing (PTB) [38].

4. Pin suspension [37-38].

Outcome measures were diverse across studies, including residual limb-interface pressure, activity monitoring, pistoning, and perceptive measures. Functional level was inconsistently reported across studies. Some had detailed reporting $[36,38]$, in which case functional level ranged from K2 to K4 prosthetic users [54], and some studies did not report functional level at all. Two of the clinical studies reported accommodation time (21 d [37] and $75 \mathrm{~d}$ [38]); however, two did not. Nondisabled control subjects were not used in the interface studies. Conclusions from the interface studies are based on 43 subjects analyzed from 63 enrolled (32\% attrition), the highest attrition within any subtopic in this review. Three studies reported sex [36-38]; in these, six subjects were female. The interquartile mean age of the reported subjects' sample mean ages is 53.5 yr. Of the 63 subjects completing the included trials, 21 (33\%) lost their foot to vascular disease. Effect sizes within this section ranged from small (0.14) relative to peak pressure in stance phase [39] to large (2.28) regarding days from amputation to first steps with prosthesis [36].

Two SRs supported the interface topic [52-53]. Two and five databases, respectively, were searched in the included reviews. Both reviews had moderate bias risk [52-53].

Following article synthesis, the following empirical evidence statements were made with regard to interfaces. In persons with TTA-

1. Compared with traditional PTB-designed interfaces, use of gel liners reportedly-

a. Decreases walk aid dependence [52].

b. Improves prosthetic suspension when used with a shuttle lock mechanism compared with supracondylar, cuff, or corset alternatives [52].

c. Improves load distribution [52-53].

d. Decreases pain and increases comfort [52-53]. 
JRRD, Volume 53, Number 2, 2016

Table 4.

Interface topic study data summary.

\begin{tabular}{|c|c|c|c|}
\hline Author & Interventions & Outcome Measures & Major Findings \\
\hline Traballesi et al., 2012 [36] & Socket, VASS + TSB. & $\begin{array}{l}\text { LCI, pain VAS, wound } \\
\text { dimensions. }\end{array}$ & $\begin{array}{l}\text { VASS allows early fitting into } \\
\text { prosthesis. }\end{array}$ \\
\hline Coleman et al., 2004 [38] & $\begin{array}{l}\text { Alpha liner vs Pelite lined } \\
\text { socket. }\end{array}$ & $\begin{array}{l}\text { Step activity monitoring, } \\
\text { PEQ, brief pain inventory, } \\
\text { socket fit comfort score, } \\
\text { residual-limb cast volume, } \\
\text { preference. }\end{array}$ & $\begin{array}{l}\text { Preference and overall ambu- } \\
\text { latory activity favored Pelite } \\
\text { over Alpha liner system. Sub- } \\
\text { jective feedback included } \\
\text { positive and negative feed- } \\
\text { back for each condition and } \\
\text { subjects expressed desire to } \\
\text { keep both study sockets. This } \\
\text { demonstrates multifactorial } \\
\text { influence regarding socket } \\
\text { selection. }\end{array}$ \\
\hline Beil et al., 2002 [39] & $\begin{array}{l}\text { Socket type: VASS vs TSB } \\
\text { design. }\end{array}$ & $\begin{array}{l}5 \text { sensors to measure residual- } \\
\text { limb pressures (positive, neg- } \\
\text { ative, peak, and impulse) in } \\
\text { gait. }\end{array}$ & $\begin{array}{l}\text { VASS changes positive and } \\
\text { negative pressures exerted on } \\
\text { residual limb during ambula- } \\
\text { tion. Impulse and peak posi- } \\
\text { tive pressures are reduced in } \\
\text { stance phase, while magni- } \\
\text { tude of impulse, average, and } \\
\text { peak negative pressures } \\
\text { increased in swing phase. }\end{array}$ \\
\hline
\end{tabular}

LCI = Locomotor Capabilities Index, PEQ = Prosthesis Evaluation Questionnaire, TSB = total surface bearing, VAS = visual analog scale, VASS = vacuum-assisted suspension system.

2. Compared with TSB-designed interfaces with pin locking suspension mechanisms, VASS interfaces reportedly-

a. Reduce time to prosthetic fitting and improve mobility postoperatively or postulceration [36].

b. Decrease step activity [37].

c. Decrease pistoning [37].

d. Decrease positive pressure in stance phase and increase negative pressure in swing phase when walking [39].

Empirical evidence statements 1a to $1 \mathrm{~d}$ are supported by SRs (level 1 evidence). Conversely, empirical evidence statements 2a to 2d are supported by single highquality clinical studies and are thus supported by level 2 evidence [22].

\section{Postoperative Care}

The three interventions studied in the postoperative care section predominantly included two basic types of postamputation dressings:

1. Plaster of Paris rigid dressing [41-44].

a. Vacuum formed [41].

b. Addition of a polymer gel sock added to rigid removable dressing (RRD) [43].

2. Elastic compression (and soft dressings) [42-44].

Additionally included in this section were two types of early postoperative prostheses or early walking aids (EWAs): articulated and nonarticulated.

Five parallel design intervention studies were included in the portion of this section on postoperative dressings (Table 5). One of these was a multisite study [42]. The total number of subjects enrolled in these studies 
Table 5.

Postoperative care topic study data summary.

\begin{tabular}{|c|c|c|c|}
\hline Author & Interventions & Outcome Measures & Major Findings \\
\hline Mazari et al., 2010 [40] & $\begin{array}{l}\text { EPOP design: articulated vs } \\
\text { nonarticulated design. }\end{array}$ & $\begin{array}{l}\text { SF-36, duration of physical } \\
\text { therapy. }\end{array}$ & $\begin{array}{l}\text { No difference in clinical and } \\
\text { QOL outcomes between artic- } \\
\text { ulated and nonarticulated } \\
\text { EWAs in rehabilitation. }\end{array}$ \\
\hline Johannesson et al., 2008 [41] & $\begin{array}{l}\text { Postamputation dressings: } \\
\text { vacuum-formed RRD vs con- } \\
\text { ventional plaster of Paris } \\
\text { removable dressing. }\end{array}$ & $\begin{array}{l}\text { Number of days from ampu- } \\
\text { tation to prosthetic fitting, } \\
\text { wound healing rate, LCI, } \\
\text { TUG. }\end{array}$ & $\begin{array}{l}\text { Results similar between } \\
\text { dressing types. Therefore, } \\
\text { post-TTA secondary to vascu- } \\
\text { lar disease, vacuum-formed } \\
\text { rigid dressing is viable alter- } \\
\text { native to conventional plaster } \\
\text { rigid dressing. }\end{array}$ \\
\hline Woodburn et al., 2004 [42] & $\begin{array}{l}\text { RRD vs soft dressing and ban- } \\
\text { daging (i.e., conventional resid- } \\
\text { ual limb dressings). }\end{array}$ & $\begin{array}{l}\text { Wound infection rate, time to } \\
\text { prosthetic fitting. }\end{array}$ & $\begin{array}{l}\text { Nonsignificant } 6 \text { d (median) } \\
\text { reduced time to prosthetic fit- } \\
\text { ting if RRD used postamputa- } \\
\text { tion. Most clinical personnel } \\
\text { expressed interest in using } \\
\text { RRDs in practice and identi- } \\
\text { fied limitations (i.e., mass) } \\
\text { could be overcome without } \\
\text { difficulty. }\end{array}$ \\
\hline Graf \& Freijah, 2003 [43] & $\begin{array}{l}\text { Polymer gel sock added to } \\
\text { RRD. }\end{array}$ & $\begin{array}{l}\text { Baseline residual-limb vol- } \\
\text { ume, volume remeasured at } \\
\text { wound healing and again at } \\
\text { prosthetic casting. }\end{array}$ & $\begin{array}{l}\text { Elastic compression, includ- } \\
\text { ing polymer gel socks, can } \\
\text { influence rate of residual limb } \\
\text { volume reduction within first } \\
3 \text { wk postamputation. }\end{array}$ \\
\hline Vigier et al., 1999 [44] & $\begin{array}{l}\text { Plaster cast socket vs elastic } \\
\text { compression. }\end{array}$ & $\begin{array}{l}\text { Time required for residual- } \\
\text { limb healing, length of time } \\
\text { between amputation and abil- } \\
\text { ity to walk wearing contact } \\
\text { socket, length of hospital stay. }\end{array}$ & $\begin{array}{l}\text { Use of plaster cast socket for } \\
\text { persons with open residual } \\
\text { limb is good alternative to } \\
\text { elastic compression. It accel- } \\
\text { erates healing time. }\end{array}$ \\
\hline
\end{tabular}

was 288, and of these, 217 (75\%) completed the research. All subjects were of dysvascular etiology, and females comprised 26 percent of subjects in this section. Accommodation to postoperative dressing type, not reported in two studies [40,44], ranged from 3 to $7 \mathrm{~d}$. Three of the five intervention studies in this section covering the postoperative RRDs rated 7/10 methodologic quality [40-42] and the other two [43-44] rated 6/10. Common issues in this section included not blinding subjects and study raters. Mean attrition in the intervention studies in this subtopic was 17 percent, which was higher than the 11 percent in the entire review but lower than the 48 percent attrition in the two studies with high bias risk. Calculation of effect sizes within this section were limited to mean rate of volume reduction from baseline and were large (1.2) between RRDs and RRDs with gel sock [43]. The difference between elastic compression versus RRD in number of days from amputation to complete healing had a medium effect size (0.57), and days from amputation to discharge had a large effect size (0.8) [44].

Three SRs were initially included in the postoperative care topic. However, one SR, despite initial inclusion, offered no supporting statement(s) or conclusions regarding any particular intervention and was therefore unable to support or refute any empirical evidence statement in the current review [16]. Two were rated as low bias risk and one as moderate risk. Generally, the SRs cover postoperative management in terms of early ambulation and limb volume. The number of databases included in each SR was 1, 2, and 4 [16,50-51]. The portion of the 
postoperative care section addressing EWAs was supported by one intervention study [40], and functional level was not reported.

Following article synthesis, the following empirical evidence statements were made with regard to postoperative care:

1. In persons with acute TTA from vascular disease, vacuum-formed dressings are comparably effective at preparing the limb for prosthetic use and ambulation as measured by the number of days from amputation to prosthetic fitting, wound healing rate, and mobility compared with conventional Plaster of Paris dressings [41].

2. Following TTA, RRDs and semi-RRDs with or without combined elastic compression are more effective at reducing acute postamputation edema volume compared with conventional elastic compression alone [43,50-51].

3. In persons with acute TTA, RRDs, compared with soft elastic dressings and bandaging, accelerate residuallimb healing time [44,50] and reduce hospitalization time [44] and are comparably effective at reducing wound infection rate and time to prosthetic fitting [42].

4. In persons with acute TTA, articulated and nonarticulated EWAs are comparably effective at improving $10 \mathrm{~m}$ walking velocity and quality of life [40].

Empirical evidence statement 2 is supported by two SRs and a high-quality intervention study (level 1 evidence). Conversely, empirical evidence statements 1,3 , and 4 are supported by single high-quality clinical studies and are thus supported by level 2 evidence [22].

\section{Pylon}

There were no SRs supporting the pylon topic. However, five intervention trials cover two subtopics within the pylon topic: (1) telescoping and/or teletorsion pylons and (2) monolimb prostheses with integrated elliptical versus circular shaped pylons (Table 6). Of these, four studies scored 7/10 methodologic quality [45-46,48-49] and one scored 6/10 [47]. Regarding bias risk, all of these studies scored moderate bias risk except one [45], which scored a low bias risk. No studies in this section blinded the clinician or raters; however, all studies blinded subjects. Two studies $[47,49]$ used a crossover design where all other studies in this section used repeated-measures designs. A total of 54 subjects completed studies in this section: 46 persons with TTA and 8 nondisabled controls. Of the 46 subjects with TTA, 30 were of traumatic etiol- ogy and 12 were of dysvascular etiology. One study did not report sex [47], and of those that did, 97 percent were male. Functional level was not reported in two studies $[45,48]$; however, functional level was reported as K2 and above in the other studies. Accommodation time to experimental pylons ranged from $5 \mathrm{~min}$ [45] to at least $3 \mathrm{wk}$ [47]. The predominant intervention (independent variable) in the pylon topic was the Mercury teletorsion pylon (Endolite Inc; Miamisburg, Ohio) [46-47,49]; however, one study's [45] independent variable was a nontelescopic torsion adapter (4R85, Ottobock; Duderstadt, Germany), and one other study's [48] independent variable was transverse pylon shape (i.e., elliptical vs circular). The effect size for change of limb length when stepping down from height was large between teletorsion versus rigid pylon (high step: 4.3 and low step: 3.7) [46]. The effect size for difference in initial stance knee flexion angle was medium (0.67) between teletorsion versus rigid pylon [49]. Differences in peak vertical ground reaction force (vGRF) measured while using elliptical and circular shaped pylons compared with current pylons ranged from small to large (0.18-2.92) [48]. Attrition was lowest (4\%) in this review topic than in all other sections. In total, this represents four different types of pylon-related interventions:

1. Pylon with-

a. Integrated teletorsion function [46-47,49].

b. Torsion adapter unit [45].

2. Monolimb with integrated [48]

a. Circular-shaped pylon.

b. Elliptical-shaped pylon.

Following article synthesis, the following empirical evidence statements were made with regard to pylons. In community-ambulating person with TTA-

1. Compared with rigid pylons, use of telescoping and/or teletorsion pylons result in-

a. Comparable biomechanics of stepping down [46].

b. Comparable step activity and duration $[47,49]$.

c. Comparable spatiotemporal, kinetic, and most kinematic measures of level ground gait [49].

d. Comparable perceptive measures [49].

e. An extended knee position at initial contact [49].

2. Compared with rigid pylons, use of a torsion adapter results in comparable hip, knee, and ankle stability and walking speed during linear and circular walking [45].

3. Use of monolimbs with elliptical shank pylons decrease peak vGRF of the- 
Table 6.

Pylon topic study data summary.

\begin{tabular}{cll}
\hline \multicolumn{1}{c}{ Author } & \multicolumn{1}{c}{ Interventions } & \multicolumn{1}{c}{ Outcome Measures } \\
\hline Segal et al., 2010 [45] & Torsion pylon adapter. & $\begin{array}{l}\text { Stability, speed, torsion, } \\
\text { walking condition. }\end{array}$ \\
Jones et al., 2006 [46] & Endolite teletorsion pylon. & $\begin{array}{l}\text { Knee joint angular displace- } \\
\text { ment, lower-limb stiffness, } \\
\text { contact ankle angle, limb } \\
\text { shortening, peak longitudinal } \\
\text { limb force. }\end{array}$
\end{tabular}

Klute et al., 2006 [47]

Lee et al., 2006 [48]

Berge et al., 2005 [49]
Mercury teletorsion vs typical rigid pylon.

ES monolimb vs CS monolimb vs conventional prosthesis.

Mercury teletorsion vs typical rigid pylon.
Activity level (steps per day), activity duration (minutes per day).

Flexibility, stride characteristics, temporal characteristics, vGRF, subjective feedback.
Self-selected walking speed, prosthetic side step length, loading rate, decelerative peak from vGRF, knee angle at initial contact and peak pylon acceleration, weekly step count, performance questionnaire, residual-limb pain, multidimensional fatigue inventory.

\section{Major Findings}

Torsion does not have effect on stability in different walking conditions.

Subjects with TTA step down and land differently than nondisabled controls. Knee is extended and vGRF is kept anterior to knee regardless of pylon or step height. Shockabsorbing pylon did not make difference in limb mechanics compared with controls.

Subjects are equally functional regardless of shockabsorbing or rigid pylon. Intensity of vocational activities may be greater than recreational activities. Step bouts were most commonly no more than few dozen steps so prostheses should be optimized for short duration bouts.

More flexible ES monolimb reduced sound-limb vGRF at early stance phase and prosthetic-limb vGRF at terminal stance. Most subjects reported greater comfort when using current prostheses, but welcomed lighter prosthetic weight from monolimbs. Greater flexibility perceived with ES monolimb. Comparing ES with CS monolimb, all subjects perceived ES monolimb improved comfort.

Rigid and shock-absorbing pylons are equally effective for subjects with unilateral amputation. Because subjects increased knee flexion at initial contact, it seems they can modulate stiffness within residual limb relative to prosthesis. 
a. Sound limb in early stance phase compared with both the current prosthesis and the circular shank monolimb [48].

b. Prosthetic limb at terminal stance compared with circular shank monolimbs [48].

All empirical evidence statements in this section, except statement $1 \mathrm{~b}$, are supported by single high-quality clinical studies and are thus supported by level 2 evidence. Statement $1 \mathrm{~b}$ is supported by two high-quality intervention studies and is thus supported by level 1 evidence [22].

\section{DISCUSSION}

\section{Overall Strengths and Weaknesses}

Generally, all included clinical trials presented some methodological issue that compromised the generalizability and usefulness of the findings to clinical practice for TTA care. Compared with other areas of healthcare with similar patient numbers and healthcare resource expenditures, prosthetic care for TTA has had less funding and less rigorous published comparative effectiveness research. For instance, breast cancer, autoimmune deficiency syndrome, schizophrenia, and Parkinson disease reportedly had comparable prevalence to those with limb loss $(\approx 1-2$ million persons in the United States) [3,55]. Searching PubMed for these diagnostic groups by name (May 2, 2014) combined with "AND meta-analysis" yielded between 325 and 2,769 articles. Repeating this with either "transtibial" or "lower-extremity amputee" combined with "AND meta-analysis" yielded only 2 or 53 articles, respectively, which reveals a clear disparity. Each of the aforementioned diagnostic groups reportedly receive between 2 and 15 percent of NIH research funds, whereas a diagnostic grouping for persons with lowerlimb amputation is generally not reported as to its level of NIH funding [55]. Funding from NIH was notably absent from the included studies. This was surprising because several NIH institutes and centers have missions focused on health conditions that often lead to limb loss, such as diabetes, cancer, and trauma, or have missions focused on musculoskeletal rehabilitation and the care of those with limb loss.

One persistent problem is broad clinical uncertainty of effectiveness that exists between different treatment choices for TTA prosthetic care [56]. For example, there are more than 150 different prosthetic feet currently available. There is no rigorous published research showing that, within a particular class of components, one foot is superior to another, and it is possible that many are equivalent. This makes the clinical selection of foot componentry difficult at the individual patient level. At the study and policy level, the uncertainty of effectiveness issue creates disagreement about which components to include in clinical efficacy trials. Some may believe that every component requires comparison, but others may argue that a comparison of representative components from within a classification grouping is sufficient to make individual patient decisions within the clinic.

The majority of articles disclosed funding, predominantly from governmental sources. With only 5 out of 32 funding disclosures (within the feet and ankles, interface, and postoperative care topics) being from industry, the likelihood of bias from this source seemed minimal when viewed collectively. Specific to the United States, the lack of a sustained funding strategy from NIH for rehabilitation research has contributed to a void in the evidence base for amputation rehabilitation and prosthetics care [57]. It may also reduce research training opportunities for rehabilitation scientists in this area. Many of the clinical trials in this SR could have increased their PEDro scores by including simple methodological changes to their design, such as blinding raters to the condition, including an intention-to-treat analysis, or reporting data in systematic and accepted ways [18]. Other factors, like blinding the treatment for the participant, is extremely difficult in any rehabilitation research design due to the very nature of physical medicine treatments $[17,58-59]$. Nonetheless, there are limited ways to blind a placebo for prosthetics research. Subject blinding is a more difficult way to improve the scientific rigor of a comparative effectiveness trial but can be accomplished in some areas of prosthetic research.

\section{Alignment}

In TTA, prosthetic foot malalignment into internal rotation compared with a patient-accepted initial alignment results in decreased gait comfort [26-27]. Involved side knee and hip kinetics appear largely unchanged, which is in contrast to the sound side knee, which presents a reduced magnitude of flexion [27]. This particular malalignment also creates mechanical inefficiency as total hip and knee work increases. These aberrant movements represent further sound side compensations. These effects on proximal contralateral joints may be related to 
decreased prosthetic shock absorption [26]. It is unclear whether these sound side changes result from a person with TTA's inability or unwillingness to load the prosthesis in stance. Perhaps stability and discomfort, caused by malalignment, influence prosthetic side stance duration, load magnitude, and movement patterns during gait.

Considering biomechanical implications of malalignment in other planes, the medially directed vector of the horizontal component of the ground reaction force (GRF) is decreased in late stance with malalignment into varus as well as internal rotation [28]. This was in contrast to malalignment into valgus and external rotation. While knowing the implications of malalignment on GRF magnitude and its associated vectors is important, the fact that adaptation and movement strategies can alter joint moments arguably make joint moments the more clinically meaningful outcome. In the aforementioned study, for instance, differences in vGRF magnitude did not translate to significant differences at proximal joint moments [28]. In fact, only external ankle moments were significantly different during the aforementioned malalignment conditions. Specifically, the ankle eversion moment was increased with malalignment of the foot into external rotation or knee into valgus. This demonstrates how movement compensations may influence kinetics. While the GRF may present asymmetrically or have differences between normal and malaligned conditions, the selected movement strategy, possibly compensated or aberrant, may mitigate the presentation via joint moment.

Implications of malalignment on spatiotemporal gait parameters seemed negligible in the included studies because only prosthetic step duration decreased with $15^{\circ}$ of prosthetic malalignment into dorsiflexion relative to the intact limb [28]. Compensations to gait malalignment and their effects are believed to be a source of premature comorbidity to limbs on both the sound and involved sides and other body regions [8]. Thus, further investigation is indicated.

Considerations regarding the perception of malalignment for prosthesis users were also studied [25]. Specifically, subjects were able to perceive only extreme coronal and sagittal malalignments. Extreme malalignments for people with TTA who use prostheses were on the order of $\geq 3^{\circ}$ angularly or $\geq 10 \mathrm{~mm}$ linearly in magnitude in both the sagittal and coronal planes and are still judged acceptable by experienced prosthetists and prosthesis users alike. An inability to perceive smaller malalignments may suggest that a broad plateau of acceptable align- ments may exist that have little effect on the transtibial prosthesis user. It is equally possible that poor alignment may contribute to a host of comorbidities observed in people with TTA related to inappropriate loading. These include residual-limb skin lesions, osteoarthritis of the sound limb, and low back pain [7-8]. Comorbidities associated with activity restriction may also result from prosthetic disuse associated with poor alignment, such as decreased physical capacity, cardiovascular disease, diabetes, and obesity. The extent to which instrumentation may be useful in the detection and correction of malalignment remains the subject of study. This is particularly true in regard to the sagittal plane [25].

While studies in the prosthetic alignment section were of high quality, there is considerable room for methodological improvement, specifically regarding concealed allocation and blinding. Functional level should absolutely be reported in every study in order to determine generalizability to clinical populations. Without reporting functional level, formulation of guidelines will be difficult. Conclusions are drawn in regard to malalignment over only minutes of adaptation, which leaves the subacute and chronic adaptations and effects of mid- and long-term malalignment completely unexplored. Given numerous descriptions of differences in Q-angle [60] and differences in footwear choices by sex, it seems that more alignment study should also involve more female subjects. It is also unknown whether tolerance of malalignment has a relationship to footwear type. Given that age has some association with walking speed, it seems that alignment may also have a relationship with either age or speed; again, the literature offers little in this area. Also unexplored is the effect of alignment on skin issues. Given the high rate of skin issues in people with lowerlimb amputation, this represents another major research gap [7].

\section{Feet and Ankles}

Four included studies measured comfortable walking speed [29-30,33-34] but only three reported units (meters per second) [29-30,34], whereas one reported the percentage of "normal" walking speed [33]. Further, where ESAR and MA component systems had sufficient data to aggregate for meta-analysis, SA, SACH, and FK units had only a single study reporting speed; thus, data were insufficient to compare. The mean walking speed was $1.24 \mathrm{~m} / \mathrm{s}$ across all studies and feet types. The mean walking speed was similar for TTA using ESAR feet 
$(1.29 \mathrm{~m} / \mathrm{s})$ or feet with MA units $(1.14 \mathrm{~m} / \mathrm{s})$. These walking speeds appear to be consistent with observational studies of persons with TTA reporting walking speeds of $1.21 \mathrm{~m} / \mathrm{s}$ [61]. They also reinforce the previously stated fact that persons with TTA walk slower than people without amputation, who tend to walk between 1.36 and $1.45 \mathrm{~m} / \mathrm{s}$ [61-62]. Perry et al. reported that people with TTA using Seattle LightFoot (ESAR) and SA feet walked significantly slower than people without amputation, whereas the walking speed with the FlexFoot (ESAR) was not significantly slower than "normal" [33]. Feet from the same functional category were evaluated and performed differently in two different studies [33-34]. This small amount of evidence suggests there may be a difference in performance within the same functional categories of feet, potentially attributable to specific foot design within the ESAR category. For instance, a flat carbon plate may store and return energy differently than a foot with an integrated J-shaped pylon during human use. According to the high-quality literature identified here, evidence statements cannot be made presently regarding the effect of prosthetic feet on walking speed. Walking speed is, however, recognized as an important determinant or indicator of function [63], and thus should be studied further given the short adaptation periods permitted in the included studies.

No studies showed significant differences in cadence between types of feet components (Figure 2). Conversely, two studies report significantly increased early stance peak plantar flexion with SA feet compared with MA and various ESAR feet [33-34]. The dilemma in interpreting this outcome is whether or not the increased sagittal range is functionally helpful. Some have noted that the faster the foot reaches foot flat, the more stable the foot is, while it may also be argued that additional muscular control and balance is needed to stabilize this added motion [64].

MA feet and ankle units are shown to have varying effects [29,34-35]. During level ground walking, Zmitrewics et al. report improved propulsion and load symmetry with MA ankle units as well as preference for them compared with the same feet without MA ankle units [29]. Postema et al. report comparable preference between MA and ESAR feet; however, MA biomechanical improvements were not identified [35]. Conversely, Underwood et al. conclude that ESAR feet increased the ability of patients to rely on the prosthesis for propulsion and stability with less compensatory motion from intact joints compared with FK feet [30]. Problematically, these studies all measured biomechanical outcomes but chose different measures and units, eliminating the possibility for aggregate analyses and conclusions [65]. Further biomechanical analyses are needed to understand potential benefits from the different categories of prosthetic feet. It is recommended that at least some of the outcome measures be selected with consideration for future meta-analyses. A starting point for selecting comparable biomechanical outcome measures could be previously outlined engineering specifications [66].

Bioenergetic measures were compared in only one included study, so meta-analyses were not possible [31]. Further complicating comparative analyses is the fact that only controlled speeds were used in the study, whereas self-selected over-ground walking speed is the velocity of choice in other studies in the review. Nonetheless, Hsu et al. report significant $(p \leq 0.05)$ mean energy reduction at all walking speeds tested between $\mathrm{SACH}$, ESAR, and ESAR with VSP feet and that these differences are of small effect sizes except the difference between SACH and ESAR with VSP (medium effect) [31]. During running, all feet were significantly different from one another; however, the effect size tended to increase to a medium magnitude. Hsu et al. conclude the addition of VSP favorably improved walking and running energy cost. Yack et al. [32] studied the same three feet classes as Hsu et al. [31]; however, Yack et al.'s study was related to stair ascent biomechanics. While VSP functional improvements could not be corroborated from a gait energy perspective, it seems that ESAR and ESAR with VSP also improve stair ascent kinetics compared with the SACH foot (large effect sizes: Cohen $d \geq$ 1.15). During stair ascent, both ESAR feet reduce the sound side compensations via hip power and moment requirements compared with SACH but the addition of VSP also seems to increase the prosthetic ankle moment [32].

Hofstad et al. conclude that insufficient evidence was available in 2009 to recommend any particular prosthetic foot over others [15]. Rather, trends were identified suggesting the FlexFoot increased stride length and improved the bioenergetics of gait for those with TTA and transfemoral amputation compared with SACH feet. This review has added two additional articles and metaanalyses on many formerly included in the Hofstad et al. review [15], which suggests that other interpretations are possible. Today, the eight evidence statements in the feet 
and ankles topic are possible to assist practitioners in selecting components in clinical practice based on certain functional requirements such as stair ascent. Many of these statements, (i.e., increased plantar flexion with SA feet) agree with the discussion and results of Hofstad et al. [15]; however, given the state of the science at that time, their discussion did not produce succinct evidence statements. With the addition of new literature and by grouping components into functional categories, alternative interpretations of available literature are possible.

Given that 58 percent of subjects lost their foot to vascular pathology and the second most represented etiology was trauma, the sample is fairly representative of demographics reported elsewhere [3]. Regarding sex, only 18 percent of subjects were female, which may cause reluctance in generalizing findings to females, particularly because perception, preference, and cosmetic considerations were not widely represented within the selected outcome measures [67]. More problematic still is subject age (interquartile mean: $46 \mathrm{yr}$ ) and the short accommodation time with feet components (30 min-4 wk). Thus, some caution is in order when attempting to broadly generalize findings from this sample of study participants because the age is younger compared with other reports [3] and the accommodation time with components is short and not representative of clinical practice in all cases. While the $4 \mathrm{wk}$ accommodation time is likely to be preferred in making prescription recommendations, it would likely extend past trial periods offered by component manufacturers and may thus be clinically impractical.

Methodologic quality was threatened and bias risk adversely affected in the feet and ankles section due generally to lack of rater and subject blinding, and no studies in the section used allocation concealment. While these additional methodologic steps do bear consideration from a fiscal and temporal perspective, they are manageable and present available opportunities for improvement upon future studies of prosthetic feet.

\section{Interface}

A single high-quality study of TTAs reported that Pelite liners were preferred by the majority of users and were associated with improved ambulatory activity and wearing time compared with Alpha liners with pin locking mechanisms [38]. This single study highlights the fact that study findings will disagree, and further, that quality, quantity, and consistency of high-quality evidence leading to a consensus is necessary to aid in pro- ducing sound evidence statements. One SR reported that walking performance and distance are positively affected by gel-lined interface systems [52]. The SR represents strong evidence [22] and is more consistent with contemporary practice. Given the disagreement between studies regarding the effect of liners on activity level and preference, further study is indicated in these areas prior to making any related empirical evidence statement.

Two SRs report the following favorable outcomes associated with liner use: improved prosthetic suspension (i.e., less pistoning); increased walking distance; decreased walk aid dependence; improved load distribution; and decreased skin irritation, abrasion, and pain [52-53]. Baars and Geertzen report increased comfort associated with liner use in 7 to 53 percent of subjects [52]. They further reported decreased pain in 19 to 53 percent of subjects when gel liners were used [52]. Liners are attractive clinically due to improvements in suspension and load distribution.

Dermatologic issues are pervasive in TTAs and are associated with liner use [52-53]. Issues include creasing at the posterior aspect of the knee joint; skin maladies such as itching, blistering, and ulceration; trapping perspiration; mechanically blocking pores; and retaining microorganisms [7,52]. Therefore, the effect of liner use on skin health is an area requiring further study. Problematically, prescription practice for specific liner selection and use is not presently well supported by the literature despite its prevalence [53]. Perhaps other outcome measures may be more relevant than those used thus far in the study of liners. Examples to consider may include interface material durability, ease and frequency of replacement, fabrication and fitting time, actual skin to interface pressure distribution, and healthcare economics.

Numerous advantages have been documented relative to VASS use compared with TSB designs and other suspension systems. These include improved fitting times following acute amputation or when an acute ulcer is present in ambulatory patients [36]. This is interesting because the application of vacuum, a recognized intervention for wound care, is supported by strong evidence but lacks conclusive evidence in nonprosthetic wound management [68]. This might suggest that combining vacuum with a prosthesis offers additional benefit for people with lower-limb amputation in a way that differs in nondisabled people with wounds. For instance, VASS provides a more consistent pressure distribution by significantly decreasing positive pressure during stance 
and increasing negative pressure during swing [39]. The increased negative swing phase pressure is corroborated by a reported decrease in pistoning with VASS use compared with a pin system [37]. However, the same study reported that VASS use decreased step activity (count) and increased fabrication time and that there was preference for pin suspension [37]. Despite the aforementioned functional outcomes, an SR reported a lack of evidence supporting the idea that "volume control" sockets (i.e., VASS) adapt to or control limb volume [51]. VASS technology seems to provide some benefits; however, more study is ultimately necessary to optimize implementation of it and to further understand more of its effects on function in patients with TTA.

Given that attrition was 32 percent (mean) as well as a lack of randomization and allocation concealment, these are clearly issues in conducting prosthetic interface studies. These are challenging but potential means to improve quality in future interface studies.

\section{Postoperative Care}

Following TTA, primarily in dysvascular patients, RRDs and semi-RRDs were found to reduce acute postamputation edema [43,50-51], healing time [44,50], hospitalization time [44], wound infection rate, and time to prosthetic fitting compared with elastic (i.e., soft) dressings [42]. This is substantiated by two low bias risk SRs [50-51]. It is important to note that the aforementioned SRs were included in this review given their rigor and publication date; however, the majority of the individual studies included within them were not included given poor methodologic quality or publication dates. Though both SRs reported sufficient data to conclude benefits associated with RRDs and semi-RRDs, both also recommended that further research was still necessary to increase confidence in the outcomes.

Vigier et al. [44] compared elastic dressings with RRDs and was included in the Nawijn et al. review [50] but not in the Sanders and Fatone review [51]. This is because limb volume was not included as a dependent variable in the study. Nevertheless, the key finding relevant here is the decreased healing time ( $25 \mathrm{~d}$; $p=0.04$ ) and hospital stay (30 d; $p=0.04$ ) related to the use of RRDs versus elastic dressings [44].

The current review also identified one additional study that contributes data to this section that was not included in the SRs. Woodburn et al. studied 112 dysvascular patients acutely following TTA [42]. Investigators studied wound infection rate and time to casting for the first prosthesis. Wound infection rate was not significantly different between RRDs and conventional nonrigid dressings. RRD use resulted in a $6 \mathrm{~d}$ median reduction in time to cast for the first prosthesis ( $p=0.23$ ). The study was stopped due to depletion of time and funding and a predictable inability to meet the necessary study sample size of 300 subjects to satisfy the a priori power and sample calculation. This resulted in a type II error and an inability to statistically validate the claim that immediate postoperative RRDs reduce infections and time to prosthetic fitting. Reasons cited by Woodburn et al. for the inability to meet the recruitment goal included numerous surgeons not participating despite expressing interest to do so and not attending training in technique. Physical therapists and nurses expressed concerns that RRDs were too heavy and may limit a patient's ability to exercise. These were not insurmountable issues if, for example, alternative materials were selected to fabricate the RRDs. Nonetheless, the majority of therapists and nurses agree that the RRDs protected the residual limb from trauma and minimized flexion contractures and the frequency of dressing changes. This newly included study's findings are consistent with previous SR findings but lack statistical power.

As previously discussed in the "Interface" section of this SR, VASS was found to reduce pistoning, improve ambulatory pressure distribution, and allow for earlier postoperative prosthetic fitting in ambulatory prostheses [36-37,39]. The addition of vacuum to postoperative dressings represents a newer application of vacuum technology as well as a novel type of acute dressing option. In nonambulatory acute, postoperative TTAs, Johannesson et al. report that vacuum-formed RRDs were not different in time from amputation to prosthetic fitting, wound healing rate, and mobility compared with conventional plaster RRDs [41].

While a key topic in postoperative TTA management is which type of dressing is most effective, another intervention consideration is related to early ambulation. Identified in the high-quality studies was "low-level evidence" supporting the addition of an early weight-bearing intervention to decrease postoperative edema again by way of an SR [51]. An additional intervention study reported no difference in walking velocity or quality of life when comparing articulated and nonarticulated early ambulatory weight-bearing interventions [40]. The latter study reported that both articulated and nonarticulated 
early weight-bearing interventions were equally effective in improving gait speed and perceptive measures of function.

Techniques to determine level of amputation and surgical methods were generally not discussed within these studies. These could be the most important factors in healing time, edema control, and weight-bearing. The Burgess technique, for instance, uses a posterior flap, while a true Ertl procedure will consider the periosteum and preserving the pressure within the medullary canal [69]. These techniques may influence edema control, hospital stay, and time to prosthetic fitting, which were all key identified outcome measures in the studies within this section. Using accepted measurements to determine the level of viable tissue prior to amputation can lead to improved outcomes [70-71]. Safety incidents that are known to occur in people with lower-limb amputation during inpatient rehabilitation, such as falls and re-injury, were also not counted in these studies [72]. Such issues can also influence measures such as time to healing or the need for surgical revision [73]. There is a known number of falls within the postoperative period that was not addressed in these studies collectively. A primary reason for using RRD versus soft dressing is residual limb protection. Knowing how an RRD was able to mitigate the damage that can occur from a fall would have an effect on the outcome. Interestingly, another reason for selecting an RRD is to visualize the wound healing progress, and compared with residual limb protection, the current SR did not find this to be a key point of emphasis. Nonetheless, it should be a consideration in the clinical selection between conventional dressings and RRDs.

Methodologic quality of studies in this section was generally 7/10, and bias risk was generally moderate. Data and conclusions are based on dysvascular subjects who are more at risk of postoperative complications. Clinicians can be confident that conclusions are generalizable to this subgroup with TTA. Conversely, outcomes are less likely to be generalizable to TTAs of traumatic etiology who tend to be younger and at less risk of postoperative complications.

\section{Pylon}

In unilateral TTAs, compared with typical rigid pylons, teletorsion pylons were equally effective in terms of the biomechanics of landing from a step down task at low $(7.3 \mathrm{~cm})$ and high $(21.9 \mathrm{~cm})$ step heights [46]; activity level and duration [47]; spatiotemporal, kinetic, and most kinematic measures of gait; and subjective measures [49]. Conversely, Berge et al. report that at controlled speed the prosthetic side knee angle is greater $(p=$ 0.004; medium effect size: 0.46 ) at initial contact with a rigid pylon whereas the shock absorbing pylon tended to result in a more extended knee during walking [49]. They report that this may be associated with subjects' attempt to modulate force attenuation relative to the stiffness of the system and that the greater knee flexion was closer to that of people without amputation [49].

Segal et al. measured lower-limb joint stability and walking speed using a torsion adapter [45]. In linear and circular walking, they report that stability and walking speed were not significantly different whether or not the torsion adapter was used. Use of the torsion adapter, however, did result in a trend of decreased stability at the prosthetic knee and ankle when subjects walked in a straight line, though the difference was not statistically significant.

In unilateral TTAs, monolimbs with elliptical shank pylons were found to significantly decrease $(p<0.05)$ peak vGRF of the sound limb at early stance phase compared with both the current (typical) prosthesis and the circular shank monolimb. Further, the elliptical-shaped monolimb decreased $(p<0.05)$ peak vGRF of the prosthetic limb at terminal stance compared with circular shank monolimbs [48]. Lee et al. maintain that such flexibility is pursued with dynamic response feet and that the elliptical-shaped monolimb is an alternative means to achieve such flexibility.

Studies in this section were also generally of moderate bias risk and 7/10 methodologic quality. No studies in the section concealed allocation or blinded clinicians or raters. Inclusion of all of these study parameters would make it possible to achieve a 9/10 or 10/10 PEDro score level. The majority of subjects studied in this section were of traumatic etiology, thereby increasing confidence in generalizing findings to this specific demographic.

\section{Limitations}

Peer-reviewed evidence represents one of three parts of evidence-based practice [74]. The other two parts that are not considered in a review such as this are patient perception and clinician experience. These other two components should not be overlooked in evidence-based practice as a whole. One reason not to omit these areas is because research and practice are sometimes in disagreement. 
Searching such a broad topic (i.e., prosthetic intervention) forces stringent limits in an effort to preserve evidence quality. As such, there may be value in more focused searching by topic (i.e., prosthetic socket) to increase the number of articles reviewed on that particular topic. One potential modification for such a strategy could be the inclusion of articles garnering a rating of $\geq 4 / 10$ on the PEDro scale compared with the $\geq 6 / 10$ criteria used here, recognizing that quality is compromised in exchange for quantity. Aiming for high-quality articles also causes topics to become limited. For example, in this SR, microprocessor foot and ankle system articles lacked the methodologic quality for inclusion in this review. Similarly, using only high-quality evidence could limit quantity as well as consistency of evidence.

Finally, there is no consensus on the best instrument and process to conduct an SR. One approach may have been to limit articles based on sample size. This approach would have further limited the number of articles included. Alternatively, we chose a reliable, internationally recognized evidence rating tool so that methods would be more universal with other reviews from around the world and to assure a quality assessment [20]. One factor that is missing from the PEDro score is some rating of the ratio of sample $(n)$ to population $(N)$ to assess the generalizability of research findings. In comparison with other healthcare treatment efficacy studies, prosthetics research has lower absolute numbers of subjects (5-20 vs $2,200-5,000$ ), but as a ratio of the sample to population $(n / N)$, the values are similar. A typical prosthetics comparative efficacy study might have an $n / N$ ratio of $15 / 1,600,000=9.375 \mathrm{E}-06$, whereas a typical cardiovascular comparative efficacy study might have an $n / N$ ratio of $2,200 / 300,000,000=7.33 \mathrm{E}-06$ [75-76]. Another interesting policy-guiding statistic might be the NIH research funding level to condition population ratio (NIH funding $/ N$ ) or NIH funding to healthcare expenditure on a particular disease or condition. Including the PEDro scale, no such funding scoring criteria are available in an evidence scoring tool.

\section{CONCLUSIONS}

From this review, 23 evidence statements supported by level 2 evidence and 8 by level 1 evidence, for a total of 31 evidence statements regarding prosthetic interventions for TTAs, were able to be generated.
It seems that transverse plane malalignment alters the biomechanics in the joints of both lower limbs. Component malalignment in the sagittal and coronal planes are detectable by the patient at an established magnitude.

Regarding prosthetic feet and ankle systems, the SA foot offers an advantage in terms of sagittal kinematics compared with MA and ESAR feet. Adding MA function to a foot, however, seems to improve involved-side kinetics. TTA use of ESAR feet seems to improve bioenergetics and prosthetic-side kinetics on both flat ground and stairs compared with SACH, FK, and MA feet; however, greater benefit in many of these areas may be experienced with the further addition of VSP function to an ESAR foot.

Regarding interfaces, use of gel liners compared with specific weight-bearing sockets improves load distribution, comfort, ambulatory independence, and suspension. Use of VASS interfaces relative to TSB reduces pistoning and time to prosthetic fitting but may come with reduced step activity. Of the topics studied, the interface topic had the highest attrition and bias risk, identifying this as an area to which greater research focus may be needed.

Postoperatively, the use of RRDs and semi-RRDs reduce postamputation edema more effectively than elastic compression alone, and the use of RRDs offers further improvements in terms of wound infection rates, healing times, and time to prosthetic fitting.

Finally, use of teletorsion pylons and torsion adapters results in comparable spatiotemporal and biomechanical gait parameters in overground walking, stepping down, and turning maneuvers relative to rigid pylons.

Overall, functional level of subjects was poorly reported. When it was reported, it was not usually done in any standardized way, thus compromising generalizability. It should be noted that with few exceptions, most of this body of work considers comfortable speed walking over flat terrain; thus, caution should be exercised when attempting to apply results beyond these conditions. It can also be concluded that the prosthetic interventions reviewed pose minimal risk and are generally safe for persons with TTA. Although high-quality literature was available to formulate evidence statements to support clinical practice in the areas of prosthetic alignment, feet and ankles, interfaces, postoperative care, and pylons, this body of evidence lacked quantity. Additionally, due to this lack of evidence, numerous topics related to care for persons with TTA were unable to be covered (i.e., microprocessor foot and ankle systems). This lack of evidence 
is at least partially attributable to a deficiency of research funding. Nevertheless, the high-quality intervention studies included characteristically incorporated randomization and data reporting that incorporated point and variance measures. The most common issues in these studies were lack of concealed allocation and blinding. It seems that the most obvious place to increase the quality of prosthetic clinical trials, based on these findings, would be to incorporate rater blinding.

\section{ACKNOWLEDGMENTS}

\section{Author Contributions:}

Study concept and design: M. J. Highsmith.

Acquisition of data: M. J. Highsmith, J. J. Orriola, R. M. Miro. Analysis and interpretation of data: M. J. Highsmith, J. T. Kahle, J. J. Orriola, J. P. Ertl, M. S. Orendurff, A. L. Lewandowski.

Drafting of manuscript: M. J. Highsmith, J. T. Kahle, M. S. Orendurff. Critical revision of manuscript for important intellectual content:

M. J. Highsmith, J. T. Kahle, R. M. Miro, M. S. Orendurff.

Statistical analysis: M. J. Highsmith, B. Sutton, R. M. Miro.

Obtained funding: M. J. Highsmith.

Administrative, technical, or material support: M. J. Highsmith, R. M. Miro.

Study supervision: M. J. Highsmith.

Financial Disclosures: The authors have declared that no competing interests exist.

Funding/Support: This material was based on work supported by the American Orthotic and Prosthetic Association (project 111012).

\section{REFERENCES}

1. Owings M, Kozak LJ. Ambulatory and inpatient procedures in the United States, 1996. Hyattsville (MD): U.S. Department of Health and Human Services, Centers for Disease Control and Prevention, National Center for Health Statistics; 1998.

2. Dillingham TR, Pezzin LE, MacKenzie EJ. Limb amputation and limb deficiency: Epidemiology and recent trends in the United States. South Med J. 2002;95(8):875-83. [PMID:12190225]

3. Ziegler-Graham K, MacKenzie EJ, Ephraim PL, Travison TG, Brookmeyer R. Estimating the prevalence of limb loss in the United States: 2005 to 2050. Arch Phys Med Rehabil. 2008;89(3):422-29. [PMID:18295618] http://dx.doi.org/10.1016/j.apmr.2007.11.005

4. Dillingham TR, Pezzin LE, Mackenzie EJ. Racial differences in the incidence of limb loss secondary to peripheral vascular disease: A population-based study. Arch Phys
Med Rehabil. 2002;83(9):1252-57. [PMID:12235605]

http://dx.doi.org/10.1053/apmr.2002.34805

5. Krueger CA, Wenke JC, Ficke JR. Ten years at war: Comprehensive analysis of amputation trends. J Trauma Acute Care Surg. 2012;73(6 Suppl 5):S438-44.

[PMID:23192067]

http://dx.doi.org/10.1097/TA.0b013e318275469c

6. Pasquina PF, Bryant PR, Huang ME, Roberts TL, Nelson VS, Flood KM. Advances in amputee care. Arch Phys Med Rehabil. 2006;87(3 Suppl 1):S34-43, quiz S44-45.

[PMID:16500191] http://dx.doi.org/10.1016/j.apmr.2005.11.026

7. Highsmith JT, Highsmith MJ. Common skin pathology in LE prosthesis users. JAAPA. 2007;20(11):33-36, 47. [PMID:18035762] http://dx.doi.org/10.1097/01720610-200711000-00018

8. Gailey R, Allen K, Castles J, Kucharik J, Roeder M. Review of secondary physical conditions associated with lower-limb amputation and long-term prosthesis use. J Rehabil Res Dev. 2008;45(1):15-29. [PMID:18566923] http://dx.doi.org/10.1682/JRRD.2006.11.0147

9. Penn-Barwell JG. Outcomes in lower limb amputation following trauma: A systematic review and meta-analysis. Injury. 2011;42(12):1474-79. [PMID:21831371] http://dx.doi.org/10.1016/j.injury.2011.07.005

10. Bragaru M, Dekker R, Geertzen JH, Dijkstra PU. Amputees and sports: A systematic review. Sports Med. 2011; 41(9):721-40. [PMID:21846162] http://dx.doi.org/10.2165/11590420-000000000-00000

11. Webster JB, Hakimi KN, Williams RM, Turner AP, Norvell DC, Czerniecki JM. Prosthetic fitting, use, and satisfaction following lower-limb amputation: A prospective study. J Rehabil Res Dev. 2012;49(10):1493-1504. [PMID:23516053] http://dx.doi.org/10.1682/JRRD.2012.01.0001

12. Blough DK, Hubbard S, McFarland LV, Smith DG, Gambel JM, Reiber GE. Prosthetic cost projections for servicemembers with major limb loss from Vietnam and OIF/OEF. J Rehabil Res Dev. 2010;47(4):387-402.

[PMID:20803406] http://dx.doi.org/10.1682/JRRD.2009.04.0037

13. Levinson DR. Questionable billing by suppliers of lower limb prostheses. OEI-02-10-00170. Washington (DC): U.S. Department of Health and Human Services, Office of the Inspector General; 2011.

14. Dillingham TR, Pezzin LE, Shore AD. Reamputation, mortality, and health care costs among persons with dysvascular lower-limb amputations. Arch Phys Med Rehabil. 2005;86(3):480-86. [PMID:15759232] http://dx.doi.org/10.1016/j.apmr.2004.06.072

15. Hofstad C, Linde H, Limbeek J, Postema K. Prescription of prosthetic ankle-foot mechanisms after lower limb 
amputation. Cochrane Database Syst Rev. 2004;(1):CD003978. [PMID:14974050]

16. Smith DG, McFarland LV, Sangeorzan BJ, Reiber GE, Czerniecki JM. Postoperative dressing and management strategies for transtibial amputations: A critical review. J Rehabil Res Dev. 2003;40(3):213-24. [PMID:14582525]

17. Highsmith MJ, Kahle JT, Bongiorni DR, Sutton BS, Groer S, Kaufman KR. Safety, energy efficiency, and cost efficacy of the C-Leg for transfemoral amputees: A review of the literature. Prosthet Orthot Int. 2010;34(4):362-77. [PMID:20969495] http://dx.doi.org/10.3109/03093646.2010.520054

18. Liberati A, Altman DG, Tetzlaff J, Mulrow C, Gøtzsche PC, Ioannidis JP, Clarke M, Devereaux PJ, Kleijnen J, Moher D. The PRISMA statement for reporting systematic reviews and meta-analyses of studies that evaluate healthcare interventions: Explanation and elaboration. BMJ. 2009;339:b2700. [PMID:19622552] http://dx.doi.org/10.1136/bmj.b2700

19. Moher D, Liberati A, Tetzlaff J, Altman DG; PRISMA Group. Preferred reporting items for systematic reviews and meta-analyses: The PRISMA statement. BMJ. 2009;339:b2535. [PMID:19622551] http://dx.doi.org/10.1136/bmj.b2535

20. Maher CG, Sherrington C, Herbert RD, Moseley AM, Elkins M. Reliability of the PEDro scale for rating quality of randomized controlled trials. Phys Ther. 2003;83(8): 713-21. [PMID:12882612]

21. Scottish Intercollegiate Guidelines Network. Critical appraisal: Notes and checklists. Methodology checklist 2: Randomised controlled trials [Internet]. Edinburgh (United Kingdom): SIGN; 2015 Jul 9 [cited 2015 Feb 1]. Available from: http://www.sign.ac.uk/methodology/checklists.html

22. Oxford Centre for Evidence-based Medicine-Levels of evidence (March 2009) [Internet]. Oxford (United Kingdom): University of Oxford; 2014 [cited 2013 Oct 1]. Available from: http://www.cebm.net/oxford-centreevidence-based-medicine-levels-evidence-march-2009

23. Neyeloff JL, Fuchs SC, Moreira LB. Meta-analyses and Forest plots using a Microsoft Excel spreadsheet: Step-bystep guide focusing on descriptive data analysis. BMC Res Notes. 2012;5:52. [PMID:22264277] http://dx.doi.org/10.1186/1756-0500-5-52

24. Cohen J. Statistical power analysis for the behavioral sciences. 2nd ed. Hillsdale (NJ): L. Erlbaum Associates; 1988.

25. Boone DA, Kobayashi T, Chou TG, Arabian AK, Coleman KL, Orendurff MS, Zhang M. Perception of socket alignment perturbations in amputees with transtibial prostheses. J Rehabil Res Dev. 2012;49(6):843-53. [PMID:23299256] http://dx.doi.org/10.1682/JRRD.2011.08.0143
26. Grumillier C, Martinet N, Paysant J, André JM, Beyaert C. Compensatory mechanism involving the hip joint of the intact limb during gait in unilateral trans-tibial amputees. J Biomech. 2008;41(14):2926-31. [PMID:18771768] http://dx.doi.org/10.1016/j.jbiomech.2008.07.018

27. Beyaert C, Grumillier C, Martinet N, Paysant J, André JM. Compensatory mechanism involving the knee joint of the intact limb during gait in unilateral below-knee amputees. Gait Posture. 2008;28(2):278-84. [PMID:18295487] http://dx.doi.org/10.1016/j.gaitpost.2007.12.073

28. Van Velzen JM, Houdijk H, Polomski W, Van Bennekom CA. Usability of gait analysis in the alignment of trans-tibial prostheses: A clinical study. Prosthet Orthot Int. 2005; 29(3):255-67. [PMID:16466155] http://dx.doi.org/10.1080/03093640500238857

29. Zmitrewicz RJ, Neptune RR, Walden JG, Rogers WE, Bosker GW. The effect of foot and ankle prosthetic components on braking and propulsive impulses during transtibial amputee gait. Arch Phys Med Rehabil. 2006;87(10):133439. [PMID:17023242]

http://dx.doi.org/10.1016/j.apmr.2006.06.013

30. Underwood HA, Tokuno CD, Eng JJ. A comparison of two prosthetic feet on the multi-joint and multi-plane kinetic gait compensations in individuals with a unilateral transtibial amputation. Clin Biomech (Bristol, Avon). 2004;19(6): 609-16. [PMID:15234485] http://dx.doi.org/10.1016/j.clinbiomech.2004.02.005

31. Hsu MJ, Nielsen DH, Yack HJ, Shurr DG. Physiological measurements of walking and running in people with transtibial amputations with 3 different prostheses. J Orthop Sports Phys Ther. 1999;29(9):526-33. [PMID:10518294] http://dx.doi.org/10.2519/jospt.1999.29.9.526

32. Yack H, Nielsen D, Shurr D. Kinetic patterns during stair ascent of patients with trans-tibial amputations wearing three different prostheses. J Prosthet Orthot. 1999;11(3): 57-62. http://dx.doi.org/10.1097/00008526-199901130-00003

33. Perry J, Boyd LA, Rao SS, Mulroy SJ. Prosthetic weight acceptance mechanics in transtibial amputees wearing the Single Axis, Seattle Lite, and Flex Foot. IEEE Trans Rehabil Eng. 1997;5(4):283-89. [PMID:9422453] http://dx.doi.org/10.1109/86.650279

34. Postema K, Hermens HJ, de Vries J, Koopman HF, Eisma WH. Energy storage and release of prosthetic feet. Part 1: Biomechanical analysis related to user benefits. Prosthet Orthot Int. 1997;21(1):17-27. [PMID:9141122]

35. Postema K, Hermens HJ, de Vries J, Koopman HF, Eisma WH. Energy storage and release of prosthetic feet. Part 2: Subjective ratings of 2 energy storing and 2 conventional feet, user choice of foot and deciding factor. Prosthet Orthot Int. 1997;21(1):28-34. [PMID:9141123]

36. Traballesi M, Delussu AS, Fusco A, Iosa M, Averna T, Pellegrini R, Brunelli S. Residual limb wounds or ulcers heal 
in transtibial amputees using an active suction socket system. A randomized controlled study. Eur J Phys Rehabil Med. 2012;48(4):613-23. [PMID:22641248]

37. Klute GK, Berge JS, Biggs W, Pongnumkul S, Popovic Z, Curless B. Vacuum-assisted socket suspension compared with pin suspension for lower extremity amputees: Effect on fit, activity, and limb volume. Arch Phys Med Rehabil. 2011;92(10):1570-75. [PMID:21963124] http://dx.doi.org/10.1016/j.apmr.2011.05.019

38. Coleman KL, Boone DA, Laing LS, Mathews DE, Smith DG. Quantification of prosthetic outcomes: Elastomeric gel liner with locking pin suspension versus polyethylene foam liner with neoprene sleeve suspension. J Rehabil Res Dev. 2004;41(4):591-602. [PMID:15558387] http://dx.doi.org/10.1682/JRRD.2004.04.0591

39. Beil TL, Street GM, Covey SJ. Interface pressures during ambulation using suction and vacuum-assisted prosthetic sockets. J Rehabil Res Dev. 2002;39(6):693-700. [PMID:17943671]

40. Mazari FA, Mockford K, Barnett C, Khan JA, Brown B, Smith L, Polman RC, Hancock A, Vanicek NK, Chetter IC. Hull early walking aid for rehabilitation of transtibial amputees_randomized controlled trial (HEART). J Vasc Surg. 2010;52(6):1564-71. [PMID:20855178] http://dx.doi.org/10.1016/j.jvs.2010.07.006

41. Johannesson A, Larsson GU, Oberg T, Atroshi I. Comparison of vacuum-formed removable rigid dressing with conventional rigid dressing after transtibial amputation: Similar outcome in a randomized controlled trial involving 27 patients. Acta Orthop. 2008;79(3):361-69.

[PMID:18622840] http://dx.doi.org/10.1080/17453670710015265

42. Woodburn KR, Sockalingham S, Gilmore H, Condie ME, Ruckley CV; Scottish Vascular Audit Group; Scottish Physiotherapy Amputee Research Group. A randomised trial of rigid stump dressing following trans-tibial amputation for peripheral arterial insufficiency. Prosthet Orthot Int. 2004;28(1):22-27. [PMID:15171574]

43. Graf M, Freijah N. Early trans-tibial oedema control using polymer gel socks. Prosthet Orthot Int. 2003;27(3):221-26. [PMID:14727703] http://dx.doi.org/10.1080/03093640308726685

44. Vigier S, Casillas JM, Dulieu V, Rouhier-Marcer I, D’Athis P, Didier JP. Healing of open stump wounds after vascular below-knee amputation: Plaster cast socket with silicone sleeve versus elastic compression. Arch Phys Med Rehabil. 1999;80(10):1327-30. [PMID:10527096] http://dx.doi.org/10.1016/S0003-9993(99)90038-2

45. Segal AD, Orendurff MS, Czerniecki JM, Shofer JB, Klute GK. Local dynamic stability of amputees wearing a torsion adapter compared to a rigid adapter during straight-line and turning gait. J Biomech. 2010;43(14):2798-2803.

\section{[PMID:20719315]}

http://dx.doi.org/10.1016/j.jbiomech.2010.05.038

46. Jones SF, Twigg PC, Scally AJ, Buckley JG. The mechanics of landing when stepping down in unilateral lower-limb amputees. Clin Biomech (Bristol, Avon). 2006;21(2):18493. [PMID:16274904]

http://dx.doi.org/10.1016/j.clinbiomech.2005.09.015

47. Klute GK, Berge JS, Orendurff MS, Williams RM, Czerniecki JM. Prosthetic intervention effects on activity of lower-extremity amputees. Arch Phys Med Rehabil. 2006;87(5):717-22. [PMID:16635636]

http://dx.doi.org/10.1016/j.apmr.2006.02.007

48. Lee WC, Zhang M, Chan PP, Boone DA. Gait analysis of low-cost flexible-shank transtibial prostheses. IEEE Trans Neural Syst Rehabil Eng. 2006;14(3):370-77. [PMID:17009497] http://dx.doi.org/10.1109/TNSRE.2006.881540

49. Berge JS, Czerniecki JM, Klute GK. Efficacy of shockabsorbing versus rigid pylons for impact reduction in transtibial amputees based on laboratory, field, and outcome metrics. J Rehabil Res Dev. 2005;42(6):795-808. [PMID:16680617] http://dx.doi.org/10.1682/JRRD.2005.02.0034

50. Nawijn SE, van der Linde H, Emmelot CH, Hofstad CJ. Stump management after trans-tibial amputation: A systematic review. Prosthet Orthot Int. 2005;29(1):13-26. [PMID:16180374] http://dx.doi.org/10.1080/17461550500066832

51. Sanders JE, Fatone S. Residual limb volume change: Systematic review of measurement and management. J Rehabil Res Dev. 2011;48(8):949-86. [PMID:22068373] http://dx.doi.org/10.1682/JRRD.2010.09.0189

52. Baars EC, Geertzen JH. Literature review of the possible advantages of silicon liner socket use in trans-tibial prostheses. Prosthet Orthot Int. 2005;29(1):27-37.

[PMID:16180375] http://dx.doi.org/10.1080/17461550500069612

53. Klute GK, Glaister BC, Berge JS. Prosthetic liners for lower limb amputees: A review of the literature. Prosthet Orthot Int. 2010;34(2):146-53. [PMID:20384553] http://dx.doi.org/10.3109/03093641003645528

54. Centers for Medicare and Medicaid Services. U.S. Department of Health and Human Services Healthcare Common Procedure Coding System. Springfield (VA): U.S. Department of Commerce, National Technical Information Service; 2007.

55. Gillum LA, Gouveia C, Dorsey ER, Pletcher M, Mathers CD, McCulloch CE, Johnston SC. NIH disease funding levels and burden of disease. PLoS ONE. 2011;6(2): e16837. [PMID:21383981] http://dx.doi.org/10.1371/journal.pone.0016837 
56. Gifford F. Pulling the plug on clinical equipoise: A critique of Miller and Weijer. Kennedy Inst Ethics J. 2007; 17(3):203-26, discussion 227-46. [PMID:18210981] http://dx.doi.org/10.1353/ken.2007.0020

57. Craik R, Chae J. Blue ribbon panel on rehabilitation research at the NIH: A preliminary report to NICHD Council [Internet]. Washington (DC): National Institutes of Health; 2012 Jun 7 [cited 2014 May 2]. Available from: https://www.nichd.nih.gov/about/advisory/nachhd/ Documents/Blue Ribbon Panel 201205.pdf

58. Johnston MV, Sherer M, Whyte J. Applying evidence standards to rehabilitation research. Am J Phys Med Rehabil. 2006;85(4):292-309. [PMID:16554683] http://dx.doi.org/10.1097/01.phm.0000202079.58567.3b

59. Whyte J. Clinical trials in rehabilitation: What are the obstacles? Am J Phys Med Rehabil. 2003;82(10 Suppl): S16-21. [PMID:14502034] http://dx.doi.org/10.1097/01.PHM.0000086992.95121.C2

60. Oatis CA. Kinesiology: The mechanics and pathomechanics of human movement. 2nd ed. Baltimore (MD): Lippincott Williams \& Wilkins; 2009.

61. Highsmith MJ, Schulz BW, Hart-Hughes S, Latlief GA, Phillips SL. Differences in the spatiotemporal parameters of transtibial and transfemoral amputee gait. J Prosthet Orthot. 2010;22(1):26-30. http://dx.doi.org/10.1097/JPO.0b013e3181cc0e34

62. Zijlstra W. Assessment of spatio-temporal parameters during unconstrained walking. Eur J Appl Physiol. 2004;92(12):39-44. [PMID:14985994] http://dx.doi.org/10.1007/s00421-004-1041-5

63. Fritz S, Lusardi M. White paper: "Walking speed: the sixth vital sign”. J Geriatr Phys Ther. 2009;32(2):46-49. [PMID:20039582] http://dx.doi.org/10.1519/00139143-200932020-00002

64. Shurr DG, Cook TM, editors. Prosthetics and orthotics. 2nd ed. Upper Saddle River (NJ): Prentice Hall; 2002.

65. Rusaw D, Ramstrand N. Motion-analysis studies of transtibial prosthesis users: A systematic review. Prosthet Orthot Int. 2011;35(1):8-19. [PMID:21515885] http://dx.doi.org/10.1177/0309364610393060

66. American Orthotic Prosthetic Association. AOPA's prosthetic foot project report [Internet]. Alexandria (VA): American Orthotic Prosthetic Association; 2010. Available from: http://www.aopanet.org/wp-content/uploads/2013/12/ Prosthetic Foot Project.pdf

67. Highsmith MJ, Kahle JT, Knight M, Olk-Szost A, Boyd M, Miro RM. Delivery of cosmetic covers to persons with transtibial and transfemoral amputations in an outpatient prosthetic practice. Prosthet Orthot Int. 2015. Epub ahead of print. [PMID:25575552] http://dx.doi.org/10.1177/0309364614564024
68. Gregor S, Maegele M, Sauerland S, Krahn JF, Peinemann F, Lange S. Negative pressure wound therapy: A vacuum of evidence? Arch Surg. 2008;143(2):189-96.

[PMID:18283145]

http://dx.doi.org/10.1001/archsurg.2007.54

69. Pasquina PF, Cooper RA. Care of the combat amputee. Washington (DC): Borden Institute; 2009.

70. Arsenault KA, Al-Otaibi A, Devereaux PJ, Thorlund K, Tittley JG, Whitlock RP. The use of transcutaneous oximetry to predict healing complications of lower limb amputations: A systematic review and meta-analysis. Eur J Vasc Endovasc Surg. 2012;43(3):329-36. [PMID:22240334] http://dx.doi.org/10.1016/j.ejvs.2011.12.004

71. Rush RM Jr, Kjorstad R, Starnes BW, Arrington E, Devine JD, Andersen CA. Application of the Mangled Extremity Severity Score in a combat setting. Mil Med. 2007;172(7): 777-81. [PMID:17691695] http://dx.doi.org/10.7205/MILMED.172.7.777

72. Dyer D, Bouman B, Davey M, Ismond KP. An intervention program to reduce falls for adult in-patients following major lower limb amputation. Healthc Q. 2008;11(3 Spec No):117-21. [PMID:18382172]

73. Gooday HM, Hunter J. Preventing falls and stump injuries in lower limb amputees during inpatient rehabilitation: Completion of the audit cycle. Clin Rehabil. 2004; 18(4):379-90. [PMID:15180121]

http://dx.doi.org/10.1191/0269215504cr738oa

74. Sackett DL, Straus SE, Richardson WS, Rosenberg W, Haynes RB. Evidence-based medicine: How to practice and teach EBM. 2nd ed. New York (NY): Churchill Livingstone; 2000.

75. Mitchell GF, Hwang SJ, Vasan RS, Larson MG, Pencina MJ, Hamburg NM, Vita JA, Levy D, Benjamin EJ. Arterial stiffness and cardiovascular events: The Framingham Heart Study. Circulation. 2010;121(4):505-11. [PMID:20083680] http://dx.doi.org/10.1161/CIRCULATIONAHA.109.886655

76. Heidenreich PA, Trogdon JG, Khavjou OA, Butler J, Dracup K, Ezekowitz MD, Finkelstein EA, Hong Y, Johnston SC, Khera A, Lloyd-Jones DM, Nelson SA, Nichol G, Orenstein D, Wilson PW, Woo YJ; American Heart Association Advocacy Coordinating Committee; Stroke Council; Council on Cardiovascular Radiology and Intervention; Council on Clinical Cardiology; Council on Epidemiology and Prevention; Council on Arteriosclerosis; Thrombosis and Vascular Biology; Council on Cardiopulmonary; Critical Care; Perioperative and Resuscitation; Council on Cardiovascular Nursing; Council on the Kidney in Cardiovascular Disease; Council on Cardiovascular Surgery and Anesthesia, and Interdisciplinary Council on Quality of Care and Outcomes Research. Forecasting the future of cardiovascular disease in the United States: A policy statement from the American Heart Association. Circulation. 2011;123(8): 
933-44. [PMID:21262990]

http://dx.doi.org/10.1161/CIR.0b013e31820a55f5

Submitted for publication March 12, 2015. Accepted in revised form July 14, 2015.

This article and any supplementary material should be cited as follows:

Highsmith MJ, Kahle JT, Miro RM, Orendurff MS, Lewandowski AL, Orriola JJ, Sutton B, Ertl JP. Pros- thetic interventions for people with transtibial amputation: Systematic review and meta-analysis of highquality prospective literature and systematic reviews. J Rehabil Res Dev. 2016;53(2):157-84.

http://dx.doi.org/10.1682/JRRD.2015.03.0046

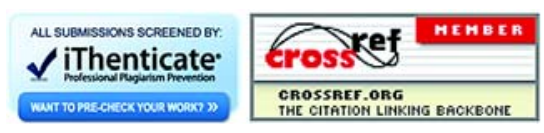


